\title{
Modeling Virus Coinfection to Inform Management of Maize Lethal Necrosis in Kenya
}

\author{
Frank M. Hilker, Linda J. S. Allen, Vrushali A. Bokil, Cheryl J. Briggs, Zhilan Feng, Karen A. Garrett, Louis J. Gross, \\ Frédéric M. Hamelin, Michael J. Jeger, Carrie A. Manore, Alison G. Power, Margaret G. Redinbaugh, Megan A. Rúa, \\ and Nik J. Cunniffe ${ }^{\dagger}$
}

First author: Institute of Environmental Systems Research, School of Mathematics/Computer Science, Osnabrück University, 49069 Osnabrück, Germany; second author: Department of Mathematics and Statistics, Texas Tech University, Lubbock 79409; third author: Department of Mathematics, Oregon State University, Corvallis 97331; fourth author: Department of Ecology, Evolution and Marine Biology, University of California, Santa Barbara 93106; fifth author: Department of Mathematics, Purdue University, West Lafayette, IN 47907; sixth author: Plant Pathology Department, Institute for Sustainable Food Systems, and Emerging Pathogens Institute, University of Florida, Gainesville 32611; seventh author: National Institute for Mathematical and Biological Synthesis, University of Tennessee, Knoxville 37996; eighth author: IGEPP, Agrocampus Ouest, INRA, Université de Rennes 1, Université Bretagne-Loire, 35000 Rennes, France; ninth author: Centre for Environmental Policy, Imperial College London, Ascot SL5 7PY, United Kingdom; tenth author: Theoretical Biology and Biophysics, Los Alamos National Laboratory, Los Alamos, NM 87544; eleventh author: Department of Ecology and Evolutionary Biology, Cornell University, Ithaca, NY 14853; twelfth author: United States Department of Agriculture-Agricultural Research Service Corn, Soybean and Wheat Quality Research Unit and Department of Plant Pathology, Ohio State University, Wooster 44691; thirteenth author: Department of Biological

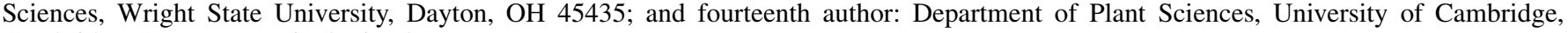
Cambridge CB2 3EA, United Kingdom.

Accepted for publication 19 May 2017.

\begin{abstract}
Maize lethal necrosis (MLN) has emerged as a serious threat to food security in sub-Saharan Africa. MLN is caused by coinfection with two viruses, Maize chlorotic mottle virus and a potyvirus, often Sugarcane mosaic virus. To better understand the dynamics of MLN and to provide insight into disease management, we modeled the spread of the viruses causing MLN within and between growing seasons. The model allows for transmission via vectors, soil, and seed, as well as exogenous sources of infection. Following model parameterization, we predict how management affects disease prevalence and crop performance over multiple seasons. Resource-rich farmers with large holdings can achieve good

control by combining clean seed and insect control. However, crop rotation is often required to effect full control. Resource-poor farmers with smaller holdings must rely on rotation and roguing, and achieve more limited control. For both types of farmer, unless management is synchronized over large areas, exogenous sources of infection can thwart control. As well as providing practical guidance, our modeling framework is potentially informative for other cropping systems in which coinfection has devastating effects. Our work also emphasizes how mathematical modeling can inform management of an emerging disease even when epidemiological information remains scanty.
\end{abstract}

Plant diseases caused by coinfecting viruses threaten food security and human health worldwide (Reynolds et al. 2015). However modeling and experimental studies often ignore coinfection, instead defaulting to the "one host-one pathogen" paradigm as a convenient simplification (Buhnerkempe et al. 2015). This is despite increasing evidence that coinfection is not only routine but can also have significant epidemiological, ecological, and evolutionary impacts (Seabloom et al. 2015; Susi et al. 2015; Tollenaere et al. 2016). Disease complexes driven by coinfecting viruses can be particularly damaging, especially when coinfection leads to significantly increased disease symptoms. An important example in a major crop is sweet potato virus disease, caused by coinfection by Sweet potato feathery mottle virus and Sweet potato chlorotic stunt virus (Kokkinos et al. 2006). Another is rice tungro disease, important throughout Southeast Asia, caused by Rice tungro bacilliform virus and Rice tungro spherical virus coinfection (Hibino et al. 1978).

†Corresponding author: N. J. Cunniffe; E-mail: njc1001@cam.ac.uk

*The $\boldsymbol{e}$-Xtra logo stands for "electronic extra" and indicates that one supplementary table is published online.

Copyright (C) 2017 The Author(s). This is an open access article distributed under the CC BY-NC-ND 4.0 International license.
A third devastating disease caused by coinfecting viruses, maize lethal necrosis (MLN), has recently emerged in East Africa (Wangai et al. 2012), East Asia (Deng et al. 2015; Xie et al. 2011), and South America (Quito-Avila et al. 2016). MLN is caused by coinfection of maize by Maize chlorotic mottle virus (MCMV) and a virus from the family Potyviridae, most commonly Wheat streak mosaic virus (WSMV), Maize dwarf mosaic virus (MDMV), or Sugarcane mosaic virus (SCMV) (Mahuku et al. 2015; Uyemoto et al. 1980). MLN induces mild to severe chlorotic mottle on leaves, necrosis developing from leaf margins to the midrib, severely reduced yield, and, eventually, plant death (Wangai et al. 2012). MLN - then called corn lethal necrosis - was first identified in 1977 in Kansas in the United States, and was shown there to be caused by the interaction of MCMV and either MDMV or WSMV (Morales et al. 2014; Niblett et al. 1978; Scheets 1998). MLN has subsequently been identified throughout the world (Adams et al. 2014; Deng et al. 2015; Lukanda et al. 2016; Mahuku et al. 2015; Quito-Avila et al. 2016; Xie et al. 2011).

In Africa, SCMV is the potyvirus most often implicated in MLN (Mahuku et al. 2015). SCMV has been present in East Africa since at least the 1970s, and the subsequent spread of MCMV in regions where SCMV is present appears to have driven the emergence of MLN (Adams et al. 2013; Louie 1980). MLN was first detected in Kenya in 2011 (Wangai et al. 2012), and has been significantly affecting maize yields since then. Approximately $22 \%$ of annual 
maize production was estimated to be lost to MLN in Kenya in 2013 (De Groote et al. 2016) and losses may be as high as $90 \%$ in heavily affected regions (Mahuku et al. 2015). Roughly $90 \%$ of the population of Kenya depends on maize for food, employment, or income (Kang'ethe 2011). Small- and medium-scale farms ( $<10$ ha) produce $75 \%$ of the nation's maize supply (Kirimi 2012) and MLN poses particular challenges to the fragile food security of resource-limited smallholders. A recent United States Department of Agriculture Foreign Agricultural Service estimate of yield loss is as high as $10 \%$ in Kenya for the 2014-15 marketing season, corresponding to a financial loss of over U.S. \$50 million (Gitonga 2014).

Transmission of both MCMV and SCMV occurs as a result of insect vectors or via seed, with evidence of additional transmission via soil. Several aphid species transmit SCMV in a nonpersistent manner (Hassan et al. 2003), and multiple insects can vector MCMV, including several species of beetles (Nault et al. 1978), as well as thrips (Cabanas et al. 2013; Moritz et al. 2013; Zhao et al. 2014). Seed transmission is also potentially important in MLN epidemiology, with vertical transmission of both viruses ( $\mathrm{Li}$ et al. 2007; Mahuku et al. 2015). Both viruses may also be soilborne (Bond et al. 1970; Mahuku et al. 2015; Phillips et al. 1982). There is considerable uncertainty surrounding the relative importance and rates of the different transmission pathways of both SCMV and MCMV, and gaps in our knowledge of the biology underpinning transmission. Nevertheless, any meaningful analysis of MLN dynamics must allow for multiple routes of spread (Fig. 1).

A number of options have been proposed to manage MLN in Kenya. Maize is often planted during two seasons in East Africa, centered on the so-called "long rains" (March to June) and "short rains" (October to December), although crops are actually in the ground either side of the rainy periods in these growing seasons. Crop rotation out of maize to a nonhost during the short-rains season may have the potential to break up the disease amplification that would occur if maize were planted during both the short and long rains. Pesticides can reduce vector populations and, therefore, reduce rates of vectored transmission of both viruses (Nelson et al.
2011), although this disease control option would generally be limited to large commercial maize farms with sufficient resources to purchase agrochemicals. In the absence of government- or non-governmental organization (NGO)-sponsored programs, external sources of virus-free "clean seed" might also be unavailable to resource-poor smallholder farmers, who could perhaps, instead, be forced to rely on simply roguing plants that are visibly affected by disease symptoms and avoiding using such plants to provide seed. Here, we will use mathematical modeling to explore the potential for success of a range of strategies for the control of MLN for both resource-poor smallholder farmers and resource-rich larger farms.

Although developing mathematical models of interactions among pathogens was recently identified as an outstanding open challenge in plant disease epidemiology (Cunniffe et al. 2015a), investigation of coinfection in systems such as MLN can draw on several types of theoretical models. One broad group of analyses has focused on using population-scale compartmental models to show how coinfection influences epidemic outcomes, modeling the effects of cross-protection (Zhang and Holt 2001) and synergism (Zhang et al. 2001) on epidemics. There are also models that track the role of infected seed or planting material (Fargette et al. 1995; Holt and Chancellor 1997; McQuaid et al. 2016; Thomas-Sharma et al. 2016, 2017; van den Bosch et al. 2007). Regular disturbance caused by repeated cycles of planting and harvesting is now much more routinely included in mathematical models of plant disease (Hamelin et al. 2011, 2016b; Madden and van den Bosch 2002; Madden et al. 2007; Mailleret et al. 2012), focusing attention on the timing of planting as another important factor, along with the effects of crop rotation (Holt and Chancellor 1997). Here, we combine elements of these previous approaches in a new model that provides a novel perspective on pathogen coinfection across multiple growing seasons for a system in which there is transmission via seed, soil, and vectors, as well as from exogenous sources of infection.

The overall goal of this article is to use mathematical modeling to better understand the processes of virus transmission that can cause MLN. The first objective underpinning model development was to evaluate the relative performance of a number of potential

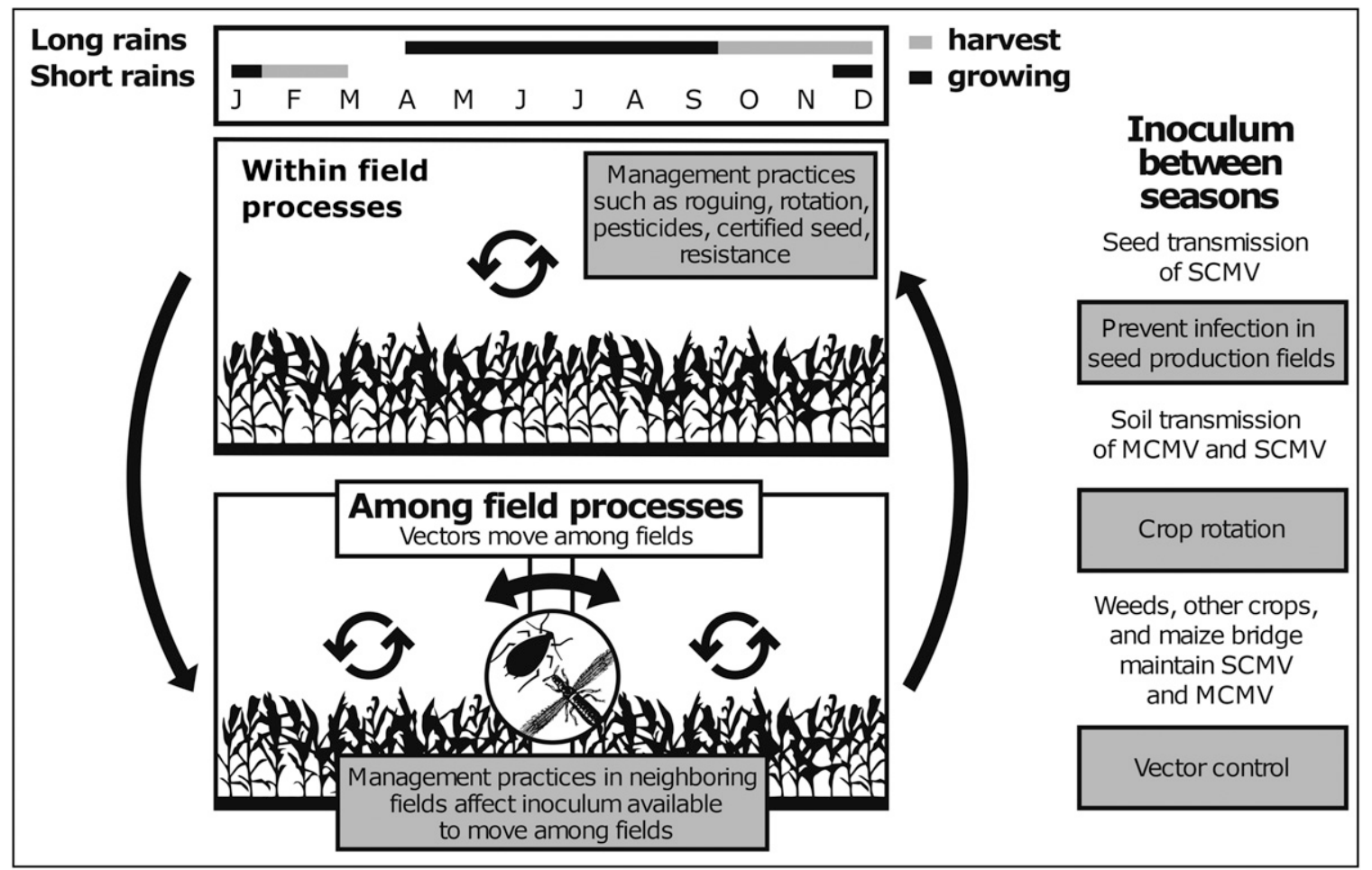

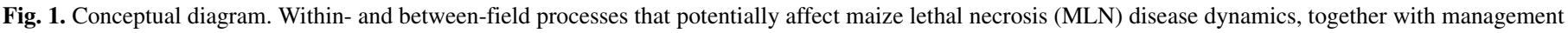
practices that can be used to control Maize chlorotic mottle virus (MCMV), Sugarcane mosaic virus (SCMV), and MLN. 
management strategies for MLN, based on the different disease control options available to resource-poor and resource-rich farmers in Kenya. The second objective was to evaluate, via sensitivity analysis, which parameters describing the epidemic are most important, to suggest follow-up experiments to better characterize MLN epidemics. We also discuss the utility of the model and its outputs in terms of guiding the formulation of management strategies and future research.

\section{MATERIALS AND METHODS}

Mathematical model. We modeled the dynamics of SCMV and MCMV infection within and between periods during which maize is grown (i.e., either the long-rains or short-rains growing season, henceforth a "season"). The model (Appendix) accounts for three modes of local virus transmission (by vectors, via seed, and from infested soil), as well as accounting for exogenous transmission from external sources of inoculum (Fig. 2). Virus spread occurs both within a season and between seasons. The within-season component maps the densities of SCMV- and MCMV-infected plants at the time of planting to those at harvest time. This part of the model accounts for within-season vectored transmission of both viruses (within a field as well as from exogenous sources of infection), together with infection of seedlings from virus-infected soil. The between-season model accounts for replenishment of the soil reservoir based on levels of infection in the preceding growing season and vertical transmission of both viruses via infected seed. A fast-slow argument (Mailleret et al. 2012) based on the relative rates of the different infection pathways is used to simplify the withinseason component of the model, allowing the within- and betweenseason models to be linked into a single model tracking the prevalence of each virus in discrete time (Appendix).

In the within-season component of the model, population densities of vectors are not modeled explicitly and, therefore, vectorborne transmission within a field simply depends on the densities of infected and uninfected plants. Infection can also occur by vectored spread from outside the focal field, such as from infected maize in neighboring fields or from alternative plant hosts. The relative importance of infection from such exogenous sources is modeled as depending on the size of the farmers' holding, with small holdings assumed to be more vulnerable due to simple area/ perimeter considerations. Within-season effects of virus coinfection are not modeled explicitly, with vectored transmission of each virus assumed to be unaffected by infection of host plants by the other virus. Although this is clearly a strong assumption, the only evidence for interactions between the viruses that lead to differences in rates of multiplication within cells comes from artificial inoculation experiments (Xia et al. 2016) or from studies of MCMV coinfecting with WSMV rather than SCMV (Scheets 1998). In both studies, rates of multiplication increased only for MCMV. To the best of our knowledge, there is also no evidence for effects of interactions on the probability of acquisition by vectors. Field data from Kenya as previously reported by Mahuku et al. (2015) additionally provide at least tentative support for the assumption of independent transmission of SCMV and MCMV (Fig. 3).

In the between-season component of the model, vertical transmission depends on how seed are sourced. Seed can either be obtained locally (i.e., saved from the previous harvest or obtained from another local farmer) or acquired from an external supplier of clean seed such as a government-certified program or an NGO. Although, in practice, there might be some low residual level of infection even on purportedly clean seed (Mezzalama et al. 2015), seed obtained from a certified seed program are assumed to be completely free of both viruses. The level of infection in seed obtained locally instead depends upon the level of infection in the previously harvested crop. In contrast to the within-season component of the model, we account for coinfection here by allowing vertical transmission of either or both viruses to potentially be more likely in the seed of MLN infected plants. Between-season transmission also depends on the level of infestation of soil from the previous season which, in turn, depends on whether maize is planted during both long and short rains. If alternate crops such as sorghum are planted, or if the field is simply left vacant during the short rains, then we assume that soil inoculum

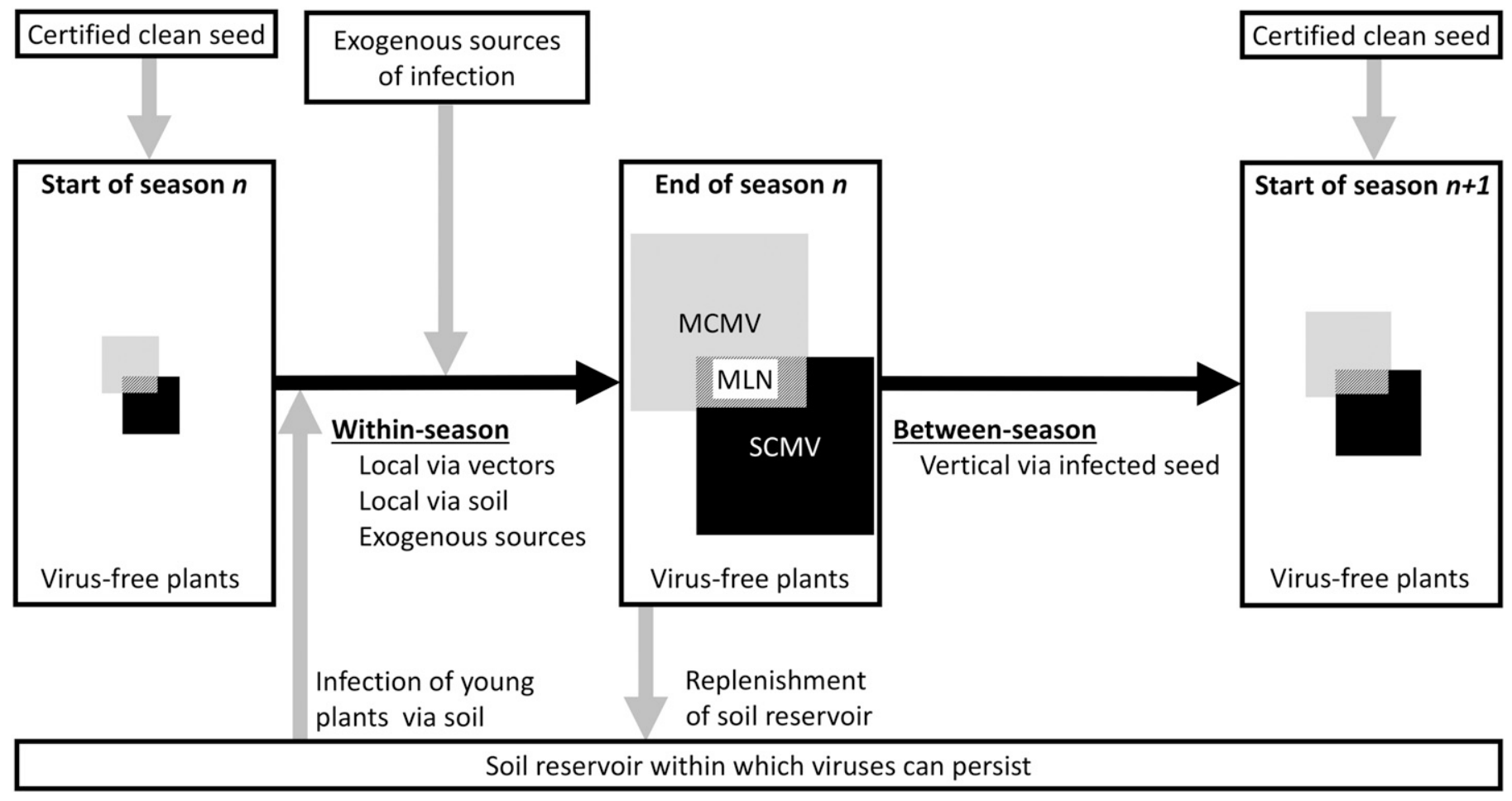

Fig. 2. Schematic showing how within-season and between-season dynamics of Maize chlorotic mottle virus (MCMV) and Sugarcane mosaic virus (SCMV) are represented in the mathematical model. MLN = maize lethal necrosis. 
is reduced to such an extent that soil transmission to the next maize crop in the following long rains is not possible (Uyemoto et al. 1980).

Model parameterization. The model requires numerical values of parameters controlling transmission from the soil $\left(\sigma_{s}\right.$ and $\left.\sigma_{m}\right)$, vertical transmission on singly $\left(\gamma_{0, s}\right.$ and $\left.\gamma_{0, m}\right)$ and coinfected $\left(\gamma_{1, s}\right.$ and $\left.\gamma_{1, m}\right)$ seed, within-field vectorborne spread $\left(\alpha_{s}\right.$ and $\left.\alpha_{m}\right)$, and exogenous infection $\left(\varepsilon_{s}\right.$ and $\left.\varepsilon_{m}\right)$, where subscripts refer to the virus in question (i.e., $s$ denotes SCMV and $m$ denotes MCMV). Model parameterization also requires values for the proportion of clean seed $(p)$, the number of plants per unit area $(N)$, and the length of the growing season $(T)$ (Table 1). We describe our baseline parameterization of the model below, noting that we later perform a sensitivity analysis to understand the potential implications of our parameter choices.

Model nondimensionalization allows the value of $N$ to be rescaled to 1 , corresponding to focusing on the proportion rather than the number of plants that become infected by each virus. Similarly, measuring time in units corresponding to the length of a growing season allows us to take $T=1$, where we have assumed that the potential for within-season virus transmission is the same during the short rains as the long rains. We also assume - at least when disease management is not attempted-that clean seed is not used and, therefore, we take $p=0$ by default. For our baseline parameterization of the model, we assume that virus transmission in seed is not affected by coinfection, although this assumption is later relaxed. For SCMV, Li et al. (2011) reported vertical transmission from

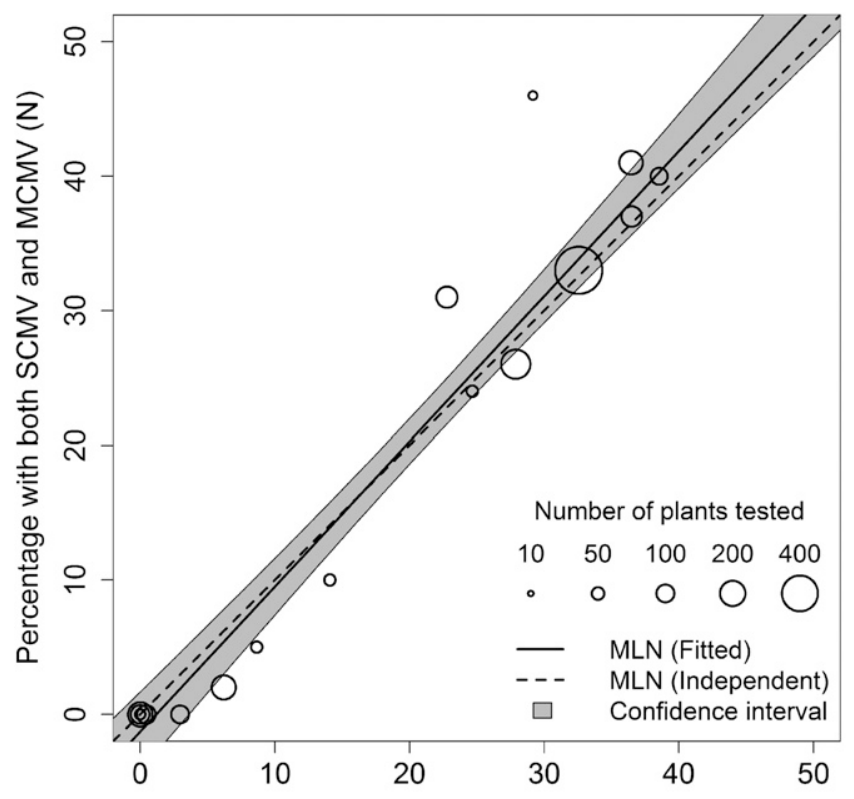

Percentage with SCMV $x$ Percentage with MCMV (S x M/100)

Fig. 3. Field data support the assumption of independent transmission of Maize chlorotic mottle virus (MCMV) and Sugarcane mosaic virus (SCMV). MLN = maize lethal necrosis. Field data as reported by Mahuku et al. (2015) are replotted, showing the results of survey D in Kenya in 2013 and 2014 (see table 3 in Mahuku et al. 2015). The result of each survey is plotted as a single circle, with area controlled by the number of plants that were tested. The value shown on the $\mathrm{x}$-axis is the product of the percentage of plants that were enzyme-linked immunosorbent assay (ELISA) positive for MCMV $(M)$ multiplied by the percentage of plants that were ELISA positive for SCMV $(S)$ (divided by 100 to recover a percentage value). The value shown on the y-axis is the percentage of plants that were simultaneously ELISA positive for both viruses $(N)$. The best-fitting linear response $\left(N=-1.28+1.08 S M ; R^{2}=0.96\right)$ obtained via weighted ordinary least squares regression is shown with a solid black line. If transmission of two viruses were independent, $N=S M$ would be expected to be an adequate model of these data. The dotted line corresponding to the assumption of independence is contained within the $95 \%$ confidence interval on the best-fitting line (gray shading; 95\% interval on the gradient of the fitted line is 0.964 to 1.194 ). approximately $3 \%$ of infected plants; therefore, we set $\gamma_{0, s}=\gamma_{1, s}=$ 0.03 . For MCMV, we take $\gamma_{0, m}=\gamma_{1, m}=0.08$ based on the proportion of vertical transmission reported by Quito-Avila et al. (2016). For our baseline parameterization of the model, we additionally assume that there is no exogenous infection and, thus, take $\varepsilon_{s}=\varepsilon_{m}=0$ by default.

Phillips et al. (1982) reported that $12 \%$ of plants become MCMV infected when maize is repeatedly planted in continuous rotation, whereas Mahuku et al. (2015) reported 69\% enzyme-linked immunosorbent assay (ELISA) positives in greenhouse experiments in which uninfected maize was planted into very heavily virus-contaminated soil. There is clearly uncertainty surrounding the relative importance of soil transmission for MCMV. To proceed with parameterization of the model, we identified the value of the parameter controlling soilborne transmission of MCMV, $\sigma_{m}=0.52$, as that value which recovers the average of the two reported figures (i.e., just over $40 \%$ ) from soil transmission alone in our model based on a $100 \%$ level of MCMV infection in the previous season (i.e., a heavy level of soil contamination). Bond et al. (1970) reported much lower transmission from soil for SCMV, with incidences of 0.7 to $5.0 \%$. Here, we parameterized our model to obtain $2.85 \%$ infection of SCMV via heavily infested soil, leading to the corresponding parameter value $\sigma_{s}=0.03$.

Mahuku et al. (2015) provided the best available data on relative levels of MCMV, SCMV, and MLN in Kenya (Fig. 3). Levels of infection varied widely by location and year, and a picture involving considerable levels of heterogeneity in levels of SCMV and MCMV infection emerged. However, focusing on the data reported for survey D in table 3 of Mahuku et al. (2015) (because only in survey $\mathrm{D}$ were samples selected at random rather than following reports of disease) and filtering out MCMV incidences less than $25 \%$ as corresponding to locations in which MCMV was not yet endemic, leads to an average MCMV prevalence in endemic areas of $70.3 \%$ (weighting the calculation of average prevalence by the size of each sample). As reported by Mahuku et al. (2015), the ELISA tests originally used to diagnose SCMV infection led to a high proportion of false negatives, suggesting survey data probably underestimate levels of SCMV infection. By combining ELISA results from tests using antisera raised to different SCMV isolates, a total of 41 SCMV positives from 83 samples gave an estimated 49.3\% SCMV incidence. Therefore, we parameterized our model such that the following endemic prevalence of each virus was obtained with all other parameters set at their default values: $\mathrm{MCMV}=70 \%$ and SCMV $=50 \%$. The only free parameters that remained to do this correspond to within-field vector transmission, $\alpha_{m}$ and $\alpha_{s}$. therefore, values of these parameters were calibrated to a single decimal place, selecting values that led to the desired long-term prevalence. This fitting procedure led to $\alpha_{m}=1.5$ (per season) and $\alpha_{s}=3.5$ (per season) for MCMV and SCMV, respectively.

Epidemiological scenarios. In assessing the performance of management options we considered the following three scenarios (Table 1).

- Baseline. The default parameterization described above.

- Coinfection effect. Here, we assume that coinfection (i.e., MLN) leads to increased vertical transmission. To illustrate potential effects of additional vertical transmission but in the absence of concrete data to parameterize the scenario, we simply assume that seed from MLN-infected plants are twice as likely to be infected with each constituent virus as seed from singly infected plants.

- Exogenous infection. Here, we assume that the focal field is subject to infection from exogenous sources of both viruses, such as infected maize grown in neighboring fields or epidemics in an alternative host such as finger millet (Kusia and Villinger 2015) or sorghum (Bockelman et al. 1982). We assume that small farms would be more affected by exogenous infection than large farms, because external inoculum would be more significant when there is a larger perimeter/area ratio, and 
take representative but arbitrary primary infection parameters $\varepsilon_{s}=\varepsilon_{m}=0.02$ per season for large farms and $\varepsilon_{s}=\varepsilon_{m}=0.1$ per season for small farms.

In both of the nonbaseline scenarios, there is a small "knock-on" effect to values of $\alpha_{m}$ and $\alpha_{s}$, which must be reestimated to attain the "target" endemic levels of each virus as described above (Table 1).

Initial conditions. We also considered three scenarios for the initial prevalences, $S_{0}$ and $M_{0}$, of SCMV and MCMV, respectively (Table 2).

- MCMV invading. Here, we assume that SCMV is initially present at its equilibrium level in the absence of MCMV, $S_{0}=$ $S^{*}$, and that the initial prevalence of MCMV is small, with $M_{0}$ corresponding to $10 \%$ of plants infected.

- Both endemic. Here, we assume that SCMV and MCMV are both present at their endemic equilibrium level initially, taking $S_{0}=S^{* *}$ and $M_{0}=M^{* *}$, respectively (the endemic level of MLN infection is therefore $\left.M^{* *} S^{* *} / N\right)$. Note that - at least when coinfected plants lead to additional vertical transmission-these coequilibrium values are different from the individual equilibria for each virus in isolation.

- Both falling. Here, we assume that control is attempted following a large outbreak of MLN and, therefore, take high initial levels of both viruses, with $S_{0}$ corresponding to $70 \%$ infection by SCMV and $M_{0}$ corresponding to $90 \%$ infection by MCMV (i.e., the starting level of each virus is approximately 20 percentage points above its equilibrium).

Disease management scenarios. We considered a total of six scenarios, distinguishing between large and small farms and allowing for no management of disease, management without crop rotation, and management with crop rotation (Table 3$)$. Small $(<10$ ha) and large farms differ in the management strategies that each can adopt, with insecticide sprays and clean seed only being possibilities for large farms and roguing only being adopted by small farms. We did not consider the effect of maize varieties with MLN tolerance, because availability of locally adapted, agronomically acceptable, tolerant hybrids is still limited.

We assumed that usage of clean seed is not perfect, and took $p=$ 0.9 . We modeled the effect of insecticide sprays on large farms by reducing the value of both vector infection parameters $\alpha_{m}$ and $\alpha_{s}$ in our model by $50 \%$. Data to support this assumption are limited and, in general, the mapping between the timing and intensity of a spray program, time-dependence in vector densities, and rates of secondary infection in our model would be extremely complex and, of course, also almost certainly different for each virus. However, we note that the assumption is in line with the overall reduction in end-of-season thrips population density in recent field trials of chemicals registered for control of thrips in Kenya (F. Miano, personal communication).

In line with our underlying assumption that soil inoculum decays very rapidly (Appendix), we assumed that crop rotation means that soil transmission does not occur and, thus, took $\sigma_{s}=\sigma_{m}=0$. We modeled the effect but not the detail of roguing by simply reducing within-season vectored spread $\left(\alpha_{s}\right.$ and $\left.\alpha_{m}\right)$ as well as betweenseason soil transmission $\left(\sigma_{s}\right.$ and $\left.\sigma_{m}\right)$, each by $10 \%$. The latter effect would follow destruction and removal of MLN-symptomatic plants at the end of a season.

Relative stand density as a measure of short-term crop performance. As well as the equilibrium levels of both viruses and the long-term prevalence of MLN infection, we introduce the "relative stand density", $Y$, as a simple measure of transient effects of disease management on crop performance and, thus, a convenient proxy for maize yield. In particular, we compared the relative percentage of plants unaffected by MLN infection over the first $T_{y}$ seasons in which maize is grown:

TABLE 1. Summary of model parameterization ${ }^{\mathrm{a}}$

\begin{tabular}{|c|c|c|c|c|c|}
\hline Parameter & Description & Baseline & Coinfection & Exogenous & Dimb $^{b}$ \\
\hline$p$ & Proportion of external clean seed & 0 & 0 & 0 & $\ldots$ \\
\hline$\gamma_{0, m}$ & Vertical transmission of MCMV from singly infected plants & 0.08 & 0.08 & 0.08 & $\ldots$ \\
\hline$\gamma_{1, m}$ & Vertical transmission of MCMV from doubly infected plants & 0.08 & 0.16 & 0.08 & $\ldots$ \\
\hline$\gamma_{1, s}$ & Vertical transmission of SCMV from doubly infected plants & 0.03 & 0.06 & 0.03 & \\
\hline$\varepsilon_{m}$ & Exogenous infection for MCMV & 0 & 0 & 0.02 (large) or 0.1 (small) & $\mathrm{T}^{-1}$ \\
\hline$\varepsilon_{s}$ & Exogenous infection for SCMV & 0 & 0 & 0.02 (large) or 0.1 (small) & $\mathrm{T}^{-1}$ \\
\hline$\sigma_{m}$ & Soil-transmission of MCMV when there is no crop rotation & 0.52 & 0.52 & 0.52 & $\mathrm{~L}^{2}$ \\
\hline$\alpha_{s}$ & Within-field SCMV infection & 3.5 & 3.2 & 3.3 (large) or 2.7 (small) & $\mathrm{L}^{2} \mathrm{~T}^{-1}$ \\
\hline$N$ & Density of plants (number of plants per area) & 1 & 1 & 1 & $\mathrm{~L}^{-2}$ \\
\hline$T$ & Length of the growing season & 1 & 1 & 1 & $\mathrm{~T}$ \\
\hline$S^{*}$ & Equilibrium prevalence of SCMV in the absence of MCMV & $50.6 \%$ & $32.9 \%$ & $51.7 \%$ & $\mathrm{~L}^{-2}$ \\
\hline$M^{*}$ & Equilibrium prevalence of MCMV in the absence of SCMV & $70.2 \%$ & $66.7 \%$ & $70.2 \%$ & $\mathrm{~L}^{-2}$ \\
\hline$S^{* *}$ & Equilibrium prevalence of SCMV when MCMV is also at equilibrium & $50.6 \%$ & $51.1 \%$ & $51.7 \%$ & $\mathrm{~L}^{-2}$ \\
\hline$M^{* *}$ & Equilibrium prevalence of MCMV when SCMV is also at equilibrium & $70.2 \%$ & $69.8 \%$ & $70.2 \%$ & $\mathrm{~L}^{-2}$ \\
\hline
\end{tabular}

${ }^{a}$ Bold indicates parameters which take different values from the baseline scenario when allowing for exogenous infection or allowing for increased vertical transmission from coinfected seed. Equilibrium values of Maize chlorotic mottle virus (MCMV) and Sugarcane mosaic virus (SCMV) are not precisely $70 \%$ and $50 \%$ for each scenario because parameters $\alpha_{m}$ and $\alpha_{s}$ were rounded to one decimal place in model calibration.

b Dimensions: $L$ refers to a measure of length (i.e., $L^{2}$ is a measure of crop area) and $T$ to a measure of time.

TABLE 2. Scenarios specifying initial conditions used in numerical simulations of the model ${ }^{\text {a }}$

\begin{tabular}{lll}
\hline Scenario & \multicolumn{1}{c}{ Initial prevalence of SCMV $\left(\mathrm{S}_{0}\right)$} & Initial prevalence of MCMV $\left(\mathrm{M}_{0}\right)$ \\
\hline MCMV invading & Equilibrium for SCMV in the absence of MCMV, $S^{*}$ & $10 \%$ \\
Both endemic & Coinfection equilibrium for SCMV, $S^{* *}$ & Coinfection equilibrium for MCMV, $M^{* *}$ \\
Both falling & $70 \%$ (i.e., approximately 20 percentage points higher & $90 \%$ (i.e., approximately 20 percentage points higher \\
& than endemic coequilibrium at which both viruses coexist) & than endemic coequilibrium at which both viruses coexist) \\
\hline
\end{tabular}

${ }^{\mathrm{a}} \mathrm{MCMV}=$ Maize chlorotic mottle virus and SCMV = Sugarcane mosaic virus. 


$$
Y=\frac{100}{T_{Y}} \sum_{t=1}^{T_{Y}}\left(1-\frac{M_{t}}{N} \frac{S_{t}}{N}\right)
$$

In comparing control strategies, we concentrated on the first five maize crops to be grown and, thus, took $T_{y}=5$ in all cases. This relatively short time scale was chosen because the effect of control is realized quite quickly in our model and because, in practice, even only a few seasons of low yields would tip the balance for resource- poor smallholder farmers. We note that $Y=100 \%$ if no plants are coinfected with the two viruses.

\section{RESULTS}

Transient dynamics. Differences in the starting prevalence of each virus can lead to large differences in levels of disease over the first few growing seasons both with and without management (Fig. 4).

TABLE 3. Management scenarios for small and large farms, both with and without crop rotation

\begin{tabular}{|c|c|c|c|c|}
\hline Scenario & Clean seed & Pesticide & Roguing & Rotation \\
\hline No control & None & None & None & None \\
\hline \multicolumn{5}{|l|}{ Small farm } \\
\hline No rotation & None & None & $\begin{array}{l}\text { Reduce } \alpha_{m} \text { and } \alpha_{s} \text { (vectors), as well as } \\
\sigma_{m} \text { and } \sigma_{s} \text { (soil) by } 10 \% \text { each }\end{array}$ & None \\
\hline With rotation & None & None & $\begin{array}{l}\text { Reduce } \alpha_{m} \text { and } \alpha_{s} \text { (vectors), as well as } \\
\sigma_{m} \text { and } \sigma_{s} \text { (soil) by } 10 \% \text { each }\end{array}$ & $\begin{array}{l}\text { Set } \sigma_{m} \text { and } \sigma_{s} \text { (soil) } \\
\text { to be } 0\end{array}$ \\
\hline \multicolumn{5}{|c|}{ 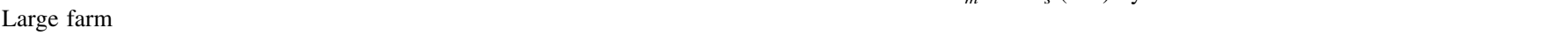 } \\
\hline No rotation & Clean seed proportion $p=0.9$ & Reduce $\alpha_{m}$ and $\alpha_{s}$ (vectors) by $50 \%$ & None & None \\
\hline
\end{tabular}

A

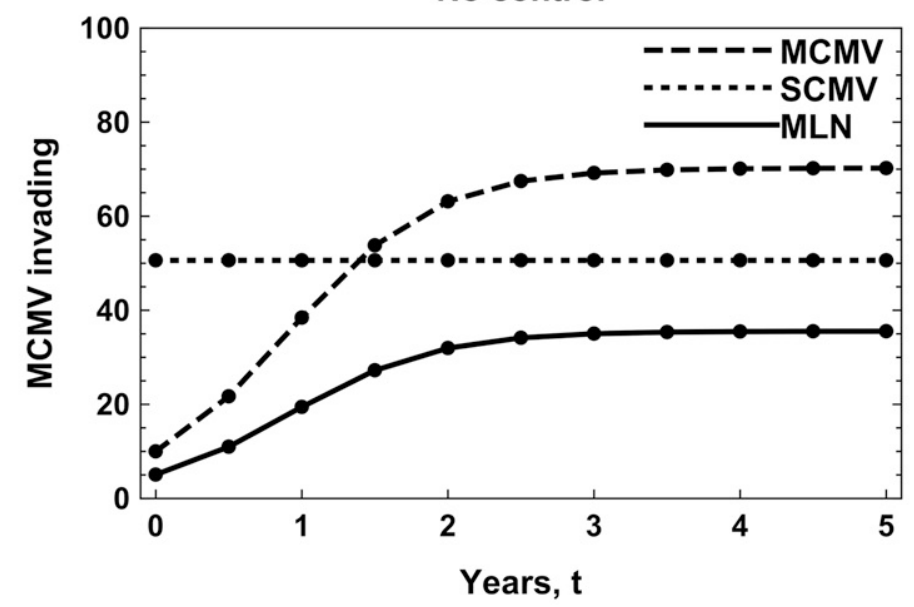

C

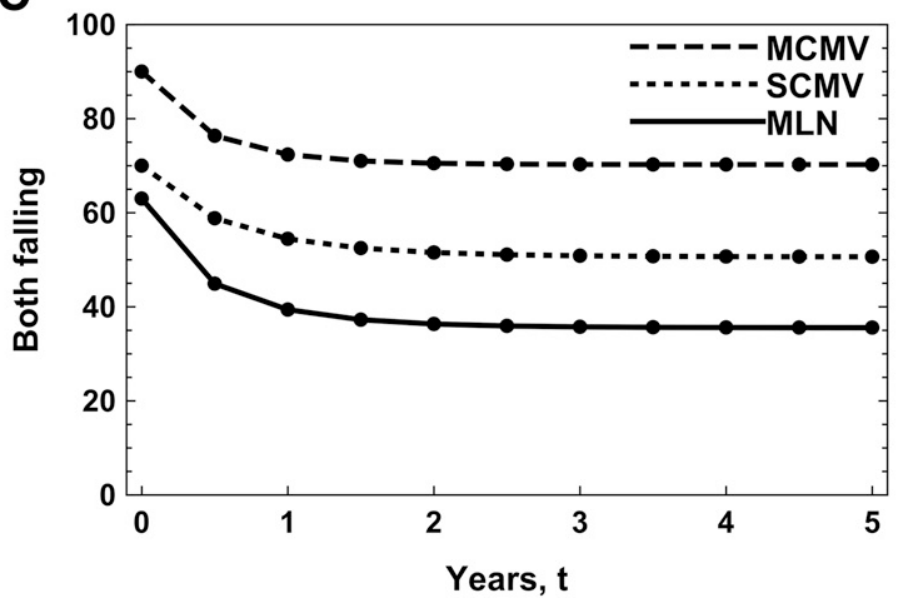

B

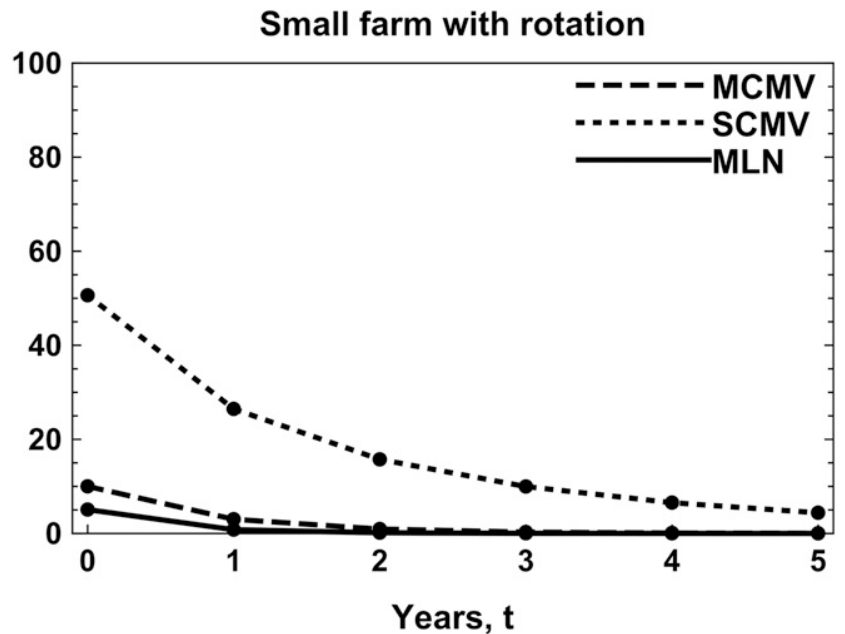

D

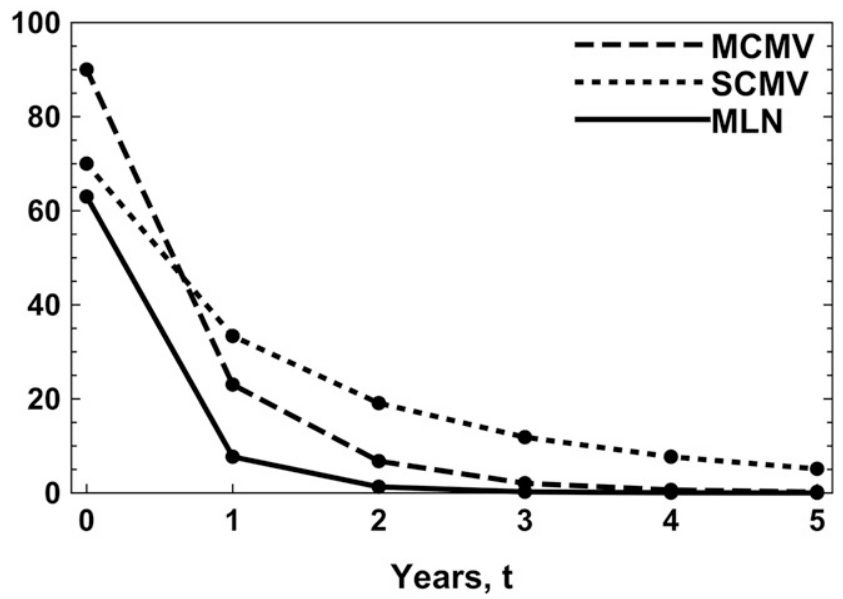

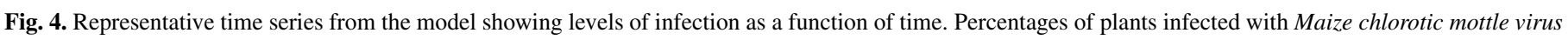

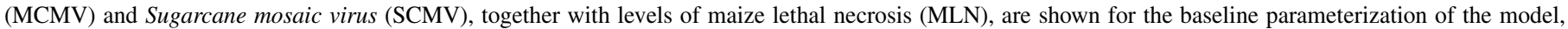

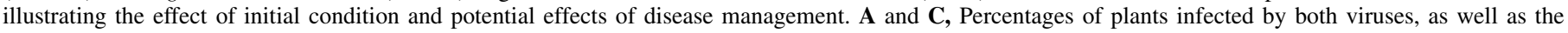

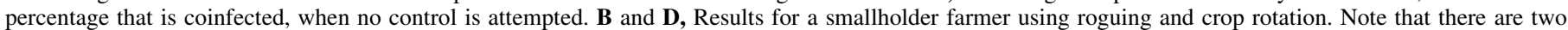

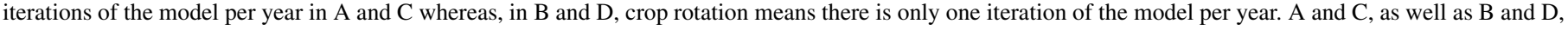

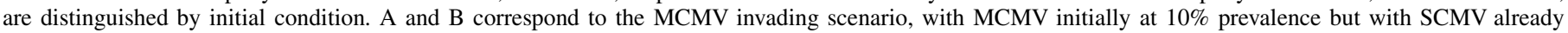

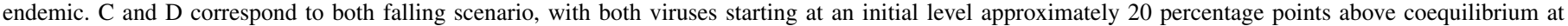
which both diseases are endemic and when no management is attempted. 
However, equilibrium levels are almost always attained within a relatively small number of successive maize growing seasons, even if there is a large deviation from the terminal level initially. We note that the prevalence of each virus tends to a constant equilibrium level, and the complex dynamics that are sometimes possible in discrete-time models-including periodic oscillations or chaotic behavior (Allen (2007)) — are not exhibited by our model, at least for any parameter combinations used here. We also note that the equilibrium levels of each virus and, therefore, the final level of
MLN coinfection also is not affected by initial conditions, at least for our default model parameterization. The model also appeared to have a unique coexistence equilibrium, and this was the case for all three parameter scenarios explored in this article.

Effect of management on short-term stand density. The potentially significant effect of transient behavior in model predictions is reflected in large differences between management scenarios for different initial conditions (Fig. 5), which we quantify via the short-term relative stand density (equation 1 ). The lowest
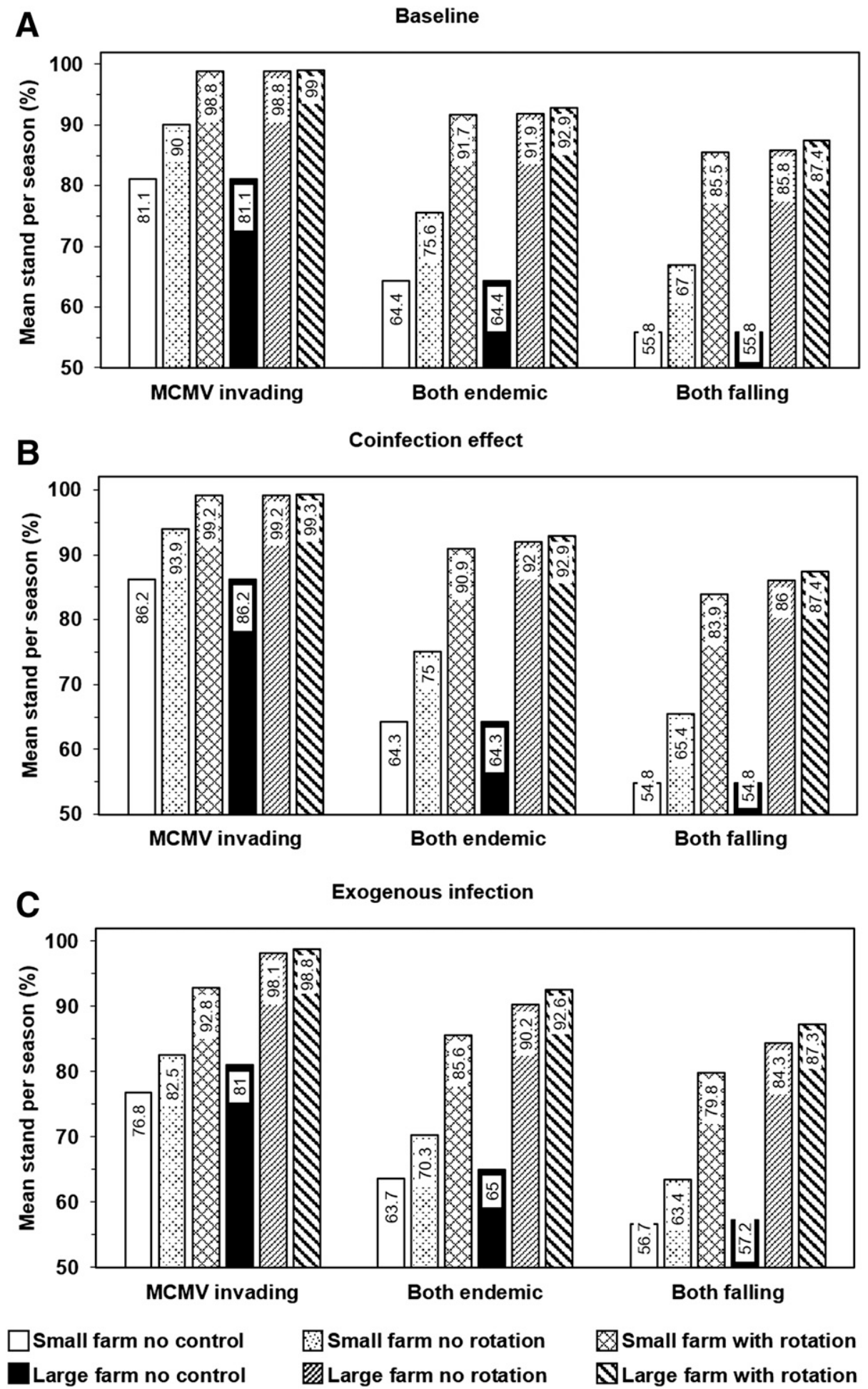

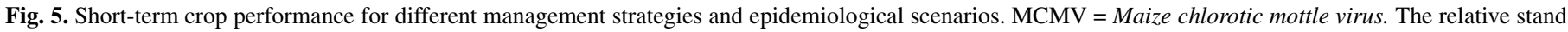

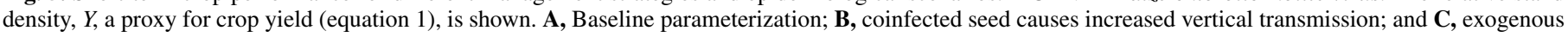

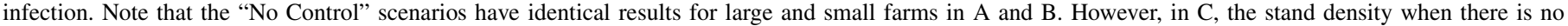
management is slightly different for large and small farms. 
average stand densities - and, therefore, the worst outcome for the farmer - are obtained if both viruses are initially at high prevalence (the both falling scenario). This scenario consistently leads to lower stand density than when both viruses start at the endemic coequilibrium (both endemic) which, in turn, consistently leads to lower stand density than when MCMV is initially at a low level (MCMV invading). This broad effect of the initial conditions was consistent for all parameter and management scenarios we tested.

A

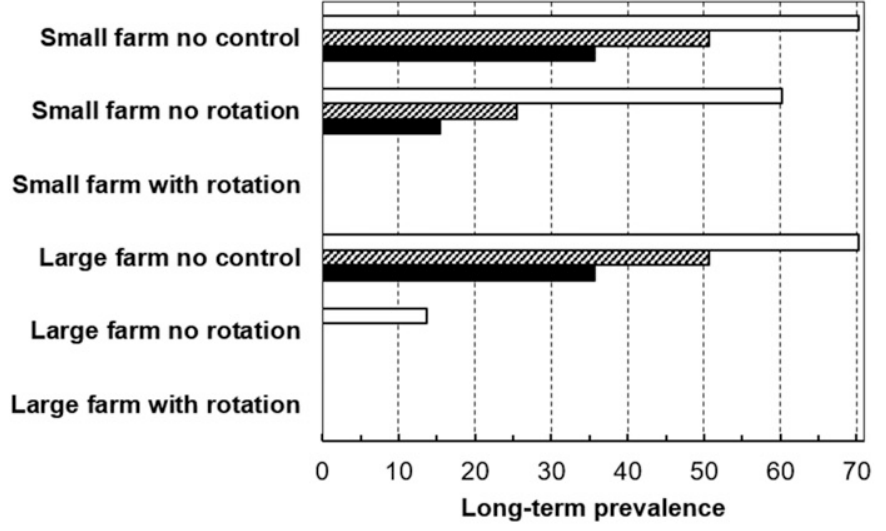

B

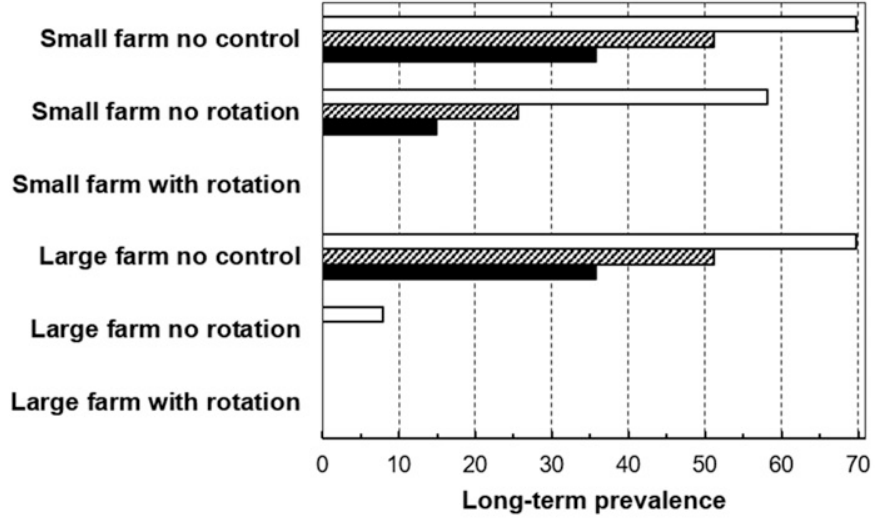

C

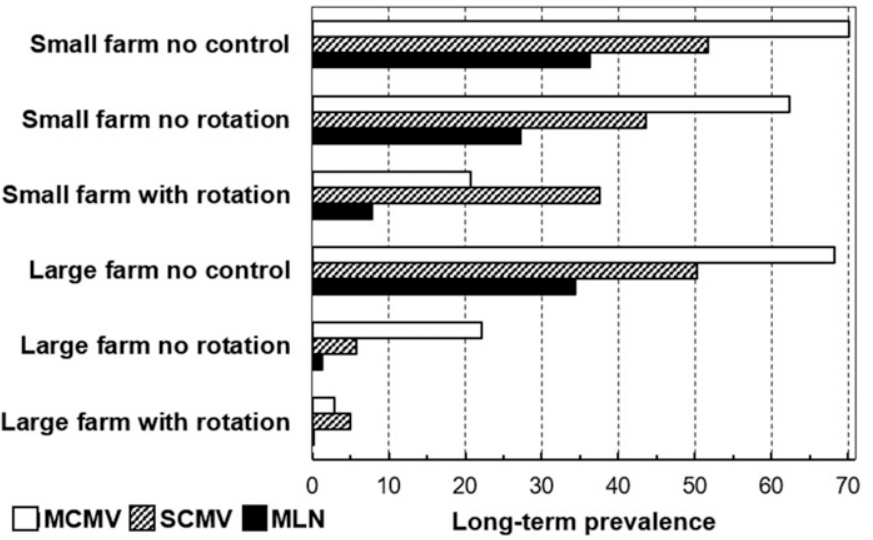

Fig. 6. Long-term Maize chlorotic mottle virus (MCMV), Sugarcane mosaic virus (SCMV), and maize lethal necrosis (MLN) prevalence for different management strategies and epidemiological scenarios, showing long-term prevalence of each virus when there is disease management, as well as the long-term prevalence of MLN. A, Baseline parameterization; B, coinfected seed causes increased vertical transmission; and $\mathbf{C}$, exogenous infection. Note that, in $\mathbf{A}$ and $\mathrm{B}$, the two "No Control" scenarios again lead to identical results whereas, in C, there is a slight difference between the results of these scenarios.
We note that large differences in short-term stand density can result from changes to initial conditions. For example, for the baseline parameter scenario when no management is attempted, there is a difference in excess of 25 percentage points in relative stand density when comparing the MCMV invading scenario $(Y=81.1 \%)$ versus the both falling scenario $(Y=55.8 \%)$.

Disease management increases the stand density, as would be expected. Large farms are expected to consistently obtain higher stand density with disease management than smallholder farmers, with crop rotation increasing stand density for both large and small farms. For example, crop rotation brings the stand density obtained by smallholder farmers to within 7 percentage points of those obtained on large farms (with or without crop rotation) under all three epidemiological scenarios if both viruses are endemic initially (Fig. 5A, B, and C; middle group of bars). In fact, similar trends are seen in all three epidemiological scenarios, with a slight tendency for higher stand densities under the coinfection scenario when MCMV is invading. However, exogenous infection tends to reduce stand densities in the MCMV invading scenario (Fig. 5C; left-hand bars). Indeed, in that initial condition scenario, stand densities with disease management for both large and small farms are strikingly high when there is no exogenous infection (Fig. 5A and B, left-hand bars). Therefore, rapid implementation of control in regions not already heavily affected by disease is expected to lead to very effective control, with average five-season stand density values potentially in excess of $90 \%$.

Effect of management on long-term prevalence. The longterm prevalence of each virus is a convenient summary of the expected effectiveness of any control that is sustained over long periods (Fig. 6). Results reinforce the idea that crop rotation can be of significant benefit to smallholder farmers, leading to eradication of MLN in the long term unless there is exogenous infection. When there is exogenous infection, however, it is impossible to totally eradicate MLN for both types of grower, no matter what management is attempted. Nevertheless, large farms practicing crop rotation are predicted to attain very low levels of disease (Fig. 6C). This suggests that area-wide management is likely to be required for control to be completely effective, because otherwise exogenous infection will thwart any control strategy from being truly successful.

Basic reproduction numbers. The response of long-term prevalence to disease management for the baseline parameter scenario can be supported by calculating the basic reproduction numbers of SCMV and MCMV (Supplementary Table S1). The basic reproduction number for MCMV invading when SCMV is absent (see also Appendix) is:

$$
\mathscr{R}_{0, m}=(\overbrace{\sigma_{m} N}^{\text {Soil }}+\overbrace{\gamma_{0, m}(1-p)}^{\text {Seed }}) \overbrace{e^{\alpha_{m} N T}}^{\text {Vector }}
$$

The corresponding quantity for SCMV invading when MCMV is absent is:

$$
\mathscr{R}_{0, s}=(\overbrace{\sigma_{s} N}^{\text {Soil }}+\overbrace{\gamma_{0, s}(1-p)}^{\text {Seed }}) \overbrace{e^{\alpha_{s} N T}}^{\text {Vector }}
$$

Therefore, both basic reproduction numbers are composed of additively and multiplicatively linked constituent parts, as is typical for plant disease models with multiple routes of transmission (Cunniffe and Gilligan 2010, 2011; Cunniffe et al. 2012; Hamelin et al. 2016a; Jeger et al. 2009).

Invasion and persistence of both viruses is necessary for MLN to occur. If the two viruses are entirely independent - as in the baseline parameter scenario-because neither virus affects the other, it is possible to define a reproductive number for MLN as simply: 


$$
R_{0}=\min \left(R_{0, \mathrm{~s}}, R_{0, \mathrm{~m}}\right)
$$

In the coinfection effect scenario, however, invasion and persistence of MLN becomes more complex. Numerical work shows that it is possible for both viruses to invade and persist in the long term even when one or the other is not able to invade in isolation. Positive feedback is possible, with more of an individual virus leading to more coinfection which, in turn, can lead to more of that virus, here via additional transmission in coinfected seed. When there is exogenous infection, both SCMV and MCMV are always able to invade and persist in the system; therefore, examination of the basic reproduction number of either virus is uninformative.

Impact of transmission pathways on long-term prevalence. We performed a sensitivity analysis by varying the parameters controlling the three routes of transmission-seed, soil, and vector-as well as the parameter corresponding to exogenous infection. We focused on the effect of these parameters on the equilibrium prevalence of MCMV and SCMV, as well as on MLN (Fig. 7). When there is no exogenous transmission (Fig. 7A to $\mathrm{C}$ and $\mathrm{E}$ to $\mathrm{G}$ ), there is almost always threshold behavior (i.e., an increase or decrease in a parameter can lead to eradication of at least one of the viruses and thus, in turn, to eradication of MLN). As a consequence of how we fitted the model, thresholds for the soil and vector transmission parameters occur at numeric values below the default parameters and the threshold for clean seed is above the default value.

When there is exogenous infection (Figs. 7D, H, and I to L), there can be no threshold effect because neither virus can be eradicated, due to repeated primary infection from neighboring fields. When there is exogenous infection, the model predicts that MLN prevalence changes relatively little with respect to the proportion of clean seed (Fig. 7I). However, reductions in soil (Fig. 7J) and vectored (Fig. 7K) transmission can greatly reduce MCMV prevalence and, thereby, reduce the prevalence of MLN. Nevertheless, if exogenous infection becomes sufficiently large, much greater than baseline values, MLN prevalence invariably approaches $100 \%$ (Fig. 7D, H, and L).

\section{DISCUSSION}

It is remarkable that MLN has emerged as such a serious threat to maize production over several continents within the last decade. The disease first emerged in the United States in the Republican River Valley of Kansas and Nebraska in the 1970s. Although MCMV remains in the area, maize thrips are absent and many maize hybrids grown in the region have potyvirus resistance. Therefore, the disease causes few agronomic problems (Jardine 2017). Initially, the disease was controlled in the United States by a 2-year moratorium on maize. Later, crop management practices were developed to tackle the disease, including crop rotation, removal of weedy virus reservoirs, and use of potyvirus-resistant and MCMV-tolerant hybrids (Phillips et al. 1982; Stewart et al. 2014; Uyemoto 1983; Uyemoto et al. 1980).

Although, since then, we have gained much information on MCMV structure, genome organization, and detection, the environmental and epidemiological factors leading to emergence and persistence remain relatively poorly understood. Because MLN is emerging in tropical and subtropical maize production systems around the world in locations where maize thrips are also present, it is also unclear whether lessons learned from its emergence in the United States can be applied directly. Certainly, some epidemiological factors,
A

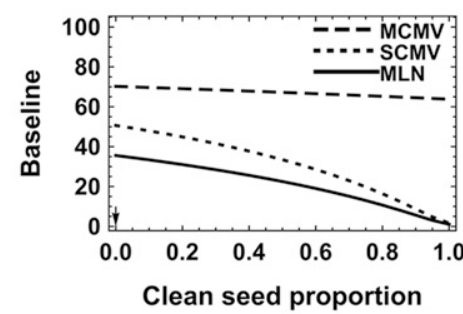

E
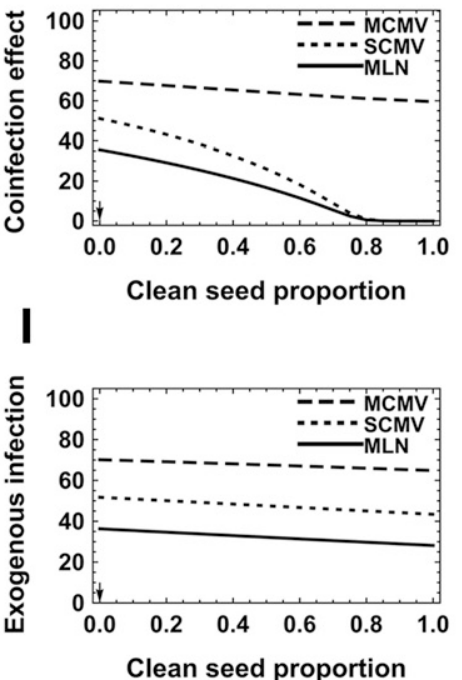

B

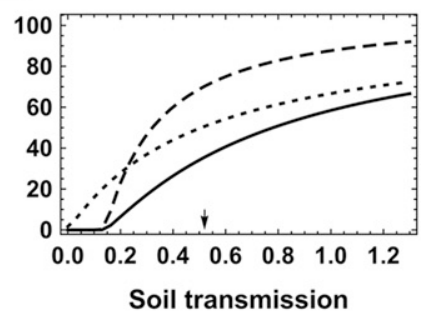

$\mathbf{F}$
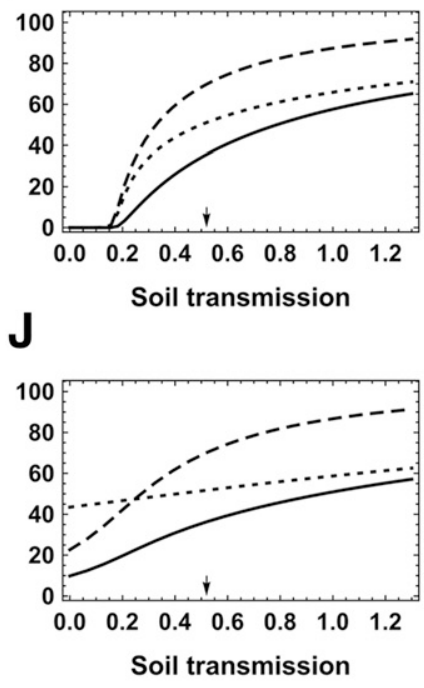

C

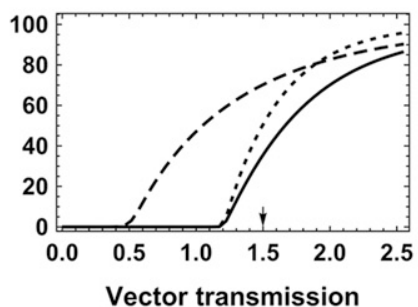

G
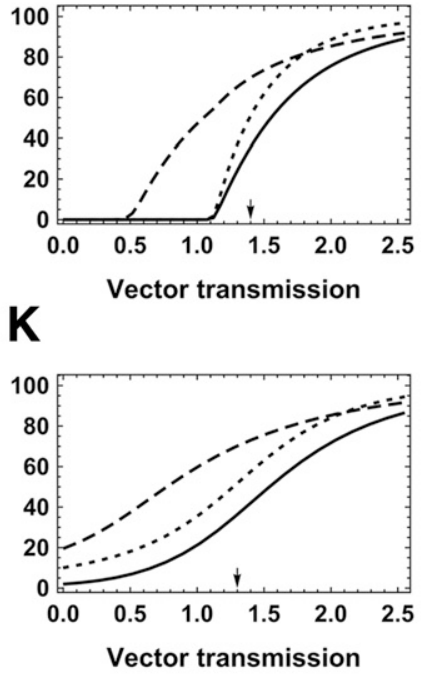

D

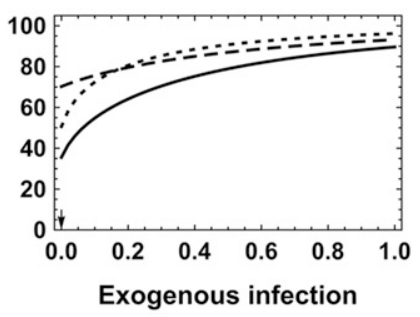

H
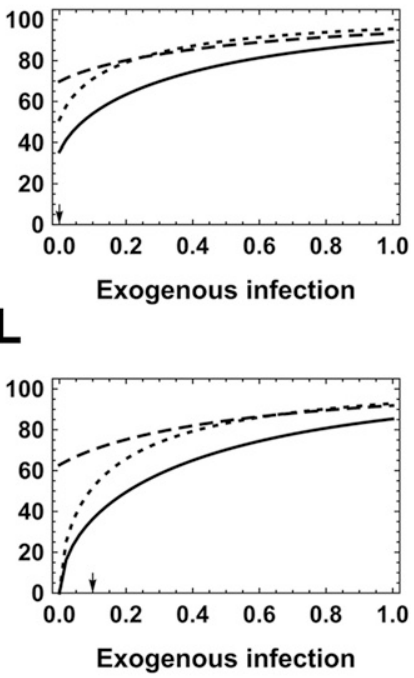

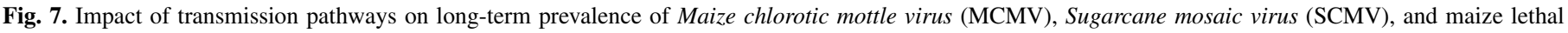

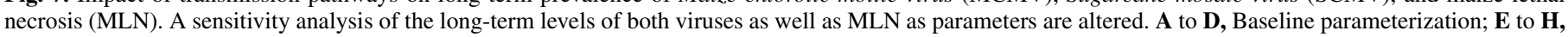

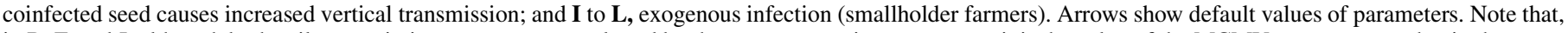

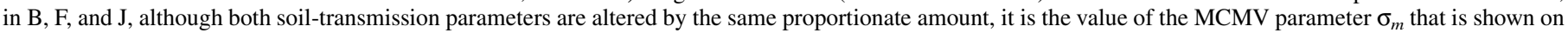

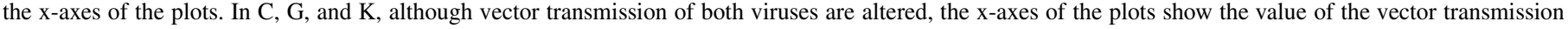
parameter for MCMV (i.e., $\alpha_{m}$ ). 
including MCMV-potyvirus interactions, vector relationships, nonvector transmission, and virus reservoirs, differ significantly between the regions. For these reasons, mathematical modeling can play an important role in integrating what biological information is available with reasonable assumptions on what is missing to give at least a first indication of the potential effectiveness of disease control options. Modeling can also indicate and help to prioritize some key research questions that need to be addressed in seeking long-term, sustainable control options.

The results of our model demonstrate that an effective level of control is potentially possible under a wide range of conditions, leading to a reduced impact of MLN on crop performance (which we quantified via the proxy of relative stand density). However, the dynamics of MLN depend upon the initial relative prevalences of SCMV and MCMV when control is first introduced (Fig. 4). If no control is practiced in an area in which SCMV is at endemic levels and MCMV is invading, then MLN emerges approximately sigmoidally over the 5-year period we considered. When crop rotation is practiced, however, the prevalence of SCMV is reduced, invasion of MCMV is delayed, and MLN is reduced to lower levels relatively quickly. If crop rotation is introduced at a time when SCMV and MCMV are both already present at high levels, then MLN again can be reduced to lower levels, indicating that crop rotation may be a very effective control measure across a wide range of initial conditions.

The effectiveness of crop rotation is also shown by comparing short-term crop performance with and without crop rotation on small and large farms (note that the latter have a wide range of control options available). Although the overall level of crop performance depends on initial conditions (highest when SCMV is endemic and MCMV is invading; lowest when both virus are at high levels), patterns in performance of different control options in each scenario are remarkably similar (Fig. 5), even when exogenous infection is included. In all cases, crop rotation carries major benefits for the smallholder farmer, echoing the earlier experience with MLN in the United States (Uyemoto 1983; Uyemoto et al. 1980). In the long term, the model indicates that, in the absence of exogenous infection, crop rotation effectively eliminates MLN for both small and large farms. However, with exogenous infection, only large farms are able to effectively eliminate MLN by means of crop rotation (Figs. 6 and 7). Because many smallholder farmers in East Africa practice mixed or relay cropping, implementing crop rotation strategies will involve significant farmer training, as well as identification of suitable rotation crops and development of markets for these crops. The importance of reducing exogenous sources of infection additionally suggests that synchronized management over large spatial extents may improve control. Although such strategies have been increasingly forcefully recommended for disease systems in the developed world-for example, diseases of citrus in Brazil (Bassanezi et al. 2013) and the United States (Gottwald and Graham 2014) - it is not clear what resources would be required to promote such coordination in East Africa.

The modeling analysis we have performed here could perhaps be extended to more directly include interactions that occur between the two coinfecting viruses within maize within a single season. In maize plants coinfected with MCMV and WSMV, MDMV, or SCMV, the titer of MCMV was found to be 1.6- to 11-fold higher than in plants infected with MCMV alone (Goldberg and Brakke 1987; Scheets 1998; Xia et al. 2016). In a reciprocal effect, titers of WSMV in doubly infected plants were also increased by two- to threefold. However, MDMV and SCMV titers were not different in singly and doubly infected plants. In all cases, the increased virus titer was associated with increased symptom severity in MLNdiseased plants. Although we did include increased seed transmission of viruses from doubly infected plants as a scenario in the modeling, other effects of coinfection were not considered, such as increased vector transmission from coinfected plants or competition between viruses. Nevertheless, including more detail on within-season effects of coinfection could affect the results of the modeling exercise, perhaps significantly. We note that-were data on the potential effect on epidemics to become available-withinseason effects of one virus on the transmission of the other could be included relatively easily in our underlying compartmental model (Zhang et al. 2001), albeit at the cost of some mathematical tractability in mapping to a discrete-time model. However, in the absence of any data to parameterize the magnitude of the effect, including within-season effects of coinfection in our default parameterization was unjustifiable. Targeted experimentation to ascertain whether or not and how within-season coinfection by MCMV and SCMV affects seed or vector transmission is arguably the key area of future research suggested by our model.

There are other areas in which further research would provide biological information that could help to improve or modify the assumptions made in the model. Vectors were not explicitly considered in the model largely for reasons of tractability in analysis but also for reasons of parsimony given the lack of information. Thrips species are assumed to be the main vectors of MCMV, whereas aphid vectors are thought to be responsible for SCMV transmission (Mahuku et al. 2015). Thrips and aphids clearly differ considerably in life histories, dispersal abilities, survival on different hosts, and virus transmission characteristics. Future modeling could incorporate some of these wide-ranging biological differences in the vector species. In modeling the effects of pesticides on large farms, we have assumed that reported reductions in numbers of thrips would be translated into proportionate reductions in transmission parameters. We consider this to be justified as a first approximation, although behavioral responses to pesticide application may also come into play. We have also assumed that the pesticide has equivalent effects on thrips and aphid transmission, again as a parsimonious response to lack of data. In analyzing the effects of exogenous inoculum, we assumed that smaller holdings would be more vulnerable; however, this would depend on the diversity and fragmentation of crops cultivated in such a holding which may, in turn, change the level of vector immigration.

Equally, the biological processes involved in transmission from a soil reservoir remain largely unknown, although preliminary experiments report that transmission from soil occurs (Mahuku et al. 2015). Feeding by the corn rootworm has been implicated for MCMV (Jensen 1985) but never confirmed as the transmission route. For SCMV, only one article (Bond et al. 1970) reported soil transmission, which is assumed to be vectored by a fungus; however, this also has never been independently confirmed. For MCMV at least, there is some evidence that the soil reservoir may persist for a period of time (Mahuku et al. 2015) but we have no information on what factors influence persistence, or how this relates to the planting of seed and seedling development. The assumption currently made is that infection from the soil reservoir occurs on a fast time scale and, therefore, only seedlings can be infected; however, further biological information could challenge this assumption. Again, the modeling exercise presented here has confirmed that further experimentation is required to understand the epidemiology of the system.

Although there is more quantitative information on levels of seed transmission of the two viruses, much of the data are based on seed testing and determining the proportion of seed infection $(\mathrm{Li}$ et al. 2007). More relevant epidemiologically is the proportion of infected seed that transfers virus infection to the developing maize plant. This may be one reason for the widely varying estimates that have been reported (Jensen et al. 1991; Quito-Avila et al. 2016). In some cases, seed from heavily coinfected maize may have lower viability and, hence, a high frequency of seed infection in one season may not translate proportionately to the next season's crop. It is also possible that MLN infection causes plants to produce fewer seed, again affecting vertical transmission. Both effects potentially warrant further study.

The effects of plant resistance or tolerance to the viruses were ignored for model development, because of the high level of MLN 
susceptibility in currently available hybrids and cultivars in East Africa (Semagn et al. 2015). Genetic resistance to potyviruses in maize is relatively well understood, and both tightly linked molecular markers and highly resistant inbred lines have been identified. Maize lines with strong resistance to MCMV remain to be identified (Redinbaugh and Zambrano 2014). However, a number of MCMV-tolerant lines, which develop few or reduced symptoms even when there is systemic infection, have been identified (Mahuku et al. 2015). Genome-wide association mapping in two populations adapted to East Africa identified several molecular markers associated with MCMV tolerance (Gowda et al. 2015) and these are currently being used in development of MLN-tolerant hybrids. It will be important to quantify the importance of MLN tolerance on disease control and spread as these materials are released to farmers, and this is another area in which mathematical modeling can potentially play a role in the future.

Simplifying assumptions had to be made concerning the effectiveness of control options to allow us to analyze the likely effectiveness of management. One of the control strategies considered was roguing. Most previous analyses of roguing have focused on perennial high-value crops (Cunniffe et al. 2014; Holt and Chancellor 1996; van den Bosch and De Roos 1996), with attention shifting more recently to consider spatially extended strategies in which asymptomatic hosts are also removed (Cunniffe et al. 2015b, 2016; Hyatt-Twynam et al. 2017; Thompson et al. 2016). The potential of roguing as a control strategy for growers of annual crops has been considered relatively rarely (Holt and Chancellor 1997). Modeling fine details of roguing is rather difficult using our model, because - at least without alteration of the formulation of the underlying continuous-time within-season models and consequent knock-on effect on model tractability - the reduction in host plant density that would occur after plants are rogued is not accounted for. It is also difficult to reconcile the assumption of independence between the two viruses with the increased level of symptoms shown by MLN plants, because these easily visible plants would be preferentially rogued. Therefore, we modeled the likely effect of roguing rather than the fine detail via changes to disease spread parameters. We also considered roguing to be practiced only by smallholder farmers, because other, potentially more effective management options were assumed to be available to large farms. In general, we note that there is a paucity of published information on the perceptions, practices, and choices made by smallholder farmers when faced with a disease such as MLN. More research on this topic would be invaluable in evaluating the feasibility and effectiveness of the control scenarios we have outlined in this article.

It is important that modeling of MLN should include key features of maize production systems. In Kenya, maize - as in most of subSaharan Africa-is a key crop for food security and the preferred crop of choice. However, production in Kenya is affected by weather conditions which, despite general patterns such as the periods of long and short rains, may be erratic and fluctuate within and between years and in the different climatic zones. We did not account for any such fluctuations or regional variation in our model. Maize farmers range in scale from smallholder farmers with limited holdings who sell only surplus grain at local markets to large-scale commercial farmers who make use of country-wide distribution networks. We modeled only the two ends of this continuum in farm size, and future work could allow heterogeneity in the size of growers' holdings to be more finely resolved. A particularly interesting further extension would be to also allow for heterogeneity in grower behavior in terms of disease control, or even responsiveness to current perceptions of disease (Milne et al. 2015).

In conclusion, MLN is an emerging virus disease with actual or potential major impact in many maize-producing regions of the world. We have used mathematical modeling to describe the dynamics of disease, with particular reference to the situation in Kenya, and, in so doing, have evaluated a set of control options that could mitigate the impact of the disease. We found that crop rotation can provide good control, particularly when combined with other control methods and when done over large spatial extents. The modeling approach is highly relevant for other regions of the world where MLN is an emerging threat to maize production. The model also introduces a new framework to address some issues relating to coinfection by different virus species, as well as characterizing novel aspects of MLN epidemiology. Analysis of the model has revealed some key areas of research, especially on vector relationships, effects of coinfection on transmission, and transmission from soil, that would improve understanding of the disease. This would help to further clarify the likelihood of success of different disease management strategies.

\section{APPENDIX}

Mathematical modeling. Overview. We initially developed continuous-time models for MCMV and SCMV infection within a single growing season. We then described how this pair of withinseason models can be extended to track the spread of disease over multiple cropping seasons by including a discrete-time component for seed and soilborne transmission between seasons. This leads to a pair of semidiscrete models for each pathogen (Madden and van den Bosch 2002; Madden et al. 2007; Mailleret et al. 2012), which are coupled together by assuming that plants coinfected with MCMV and SCMV (i.e., plants affected by MLN) potentially lead to higher vertical transmission via infected seed.

We then showed - using a fast-slow argument based on the relative rates of the different infection pathways-how the continuous-time models for within-season spread can be simplified to discrete-time models that map densities of infected plants from the start to the end of each growing season. In this fashion, we recovered our final model, which consists of a pair of coupled discrete-time mappings that track the final densities of MCMV- and SCMV-infected plants at the end of each growing season. Because we assume that within-season transmission of each virus is independent of the other, we can then recover the level of MLN infection from the outputs of these models by simply multiplying the proportion of plants infected by each virus. A summary of all state variables used in developing the final model is given in Table 4.

Within-season models. We first modeled within-season virus transmission during a single growing season, which can be either the short rains or long rains. We tracked the dynamics for $t \in[0, T]$, where $T$ is the length of the growing season. We described the within-season model for MCMV, which tracks the values of two state variables, $M(t)$ (the density of MCMV-infected plants) and $Z_{m}(t)$ (the density of MCMV soil inoculum). This component of the model accounts for vectored transmission of MCMV (both withinfield and from exogenous sources of infection), as well as infection from decaying inoculum in the soil. We assume that neither infection nor coinfection lead to within-season plant mortality and, therefore, the density of maize plants (i.e., the total number of plants per unit area) is held constant at $N$. Thus, the density of plants not infected by MCMV is $N-M(t)$. We also assume that rates of MCMV transmission within the season are not affected by whether or not a plant is infected by SCMV. Differential equations governing the rates of change of the density of plants infected with MCMV and of MCMV inoculum in the soil are therefore

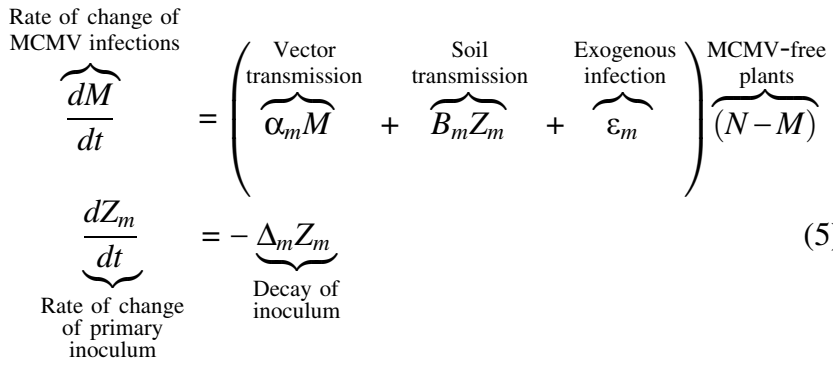

The within-season model of SCMV infection tracks the densities of SCMV-infected plants and soil inoculum- $S(t)$, and $Z_{s}(t)$, 
respectively_but is otherwise exactly like equation 5 (subscripting parameters with $s$ rather than $m$ ).

Between-season models. The between-season soil and seed transmission dynamics specify the initial conditions in the withinseason models and, in turn, depend on the prevalence of each virus at the end of the previous within-season period. Using the assumption of independence of MCMV and SCMV to define the prevalence of MLN coinfection, assuming that any nonlocally sourced clean seed is entirely free of the virus, and denoting the levels of MCMV and SCMV infection at the end of the previous growing season by $M_{n}^{T}$ and $S_{n}^{T}$, it follows that

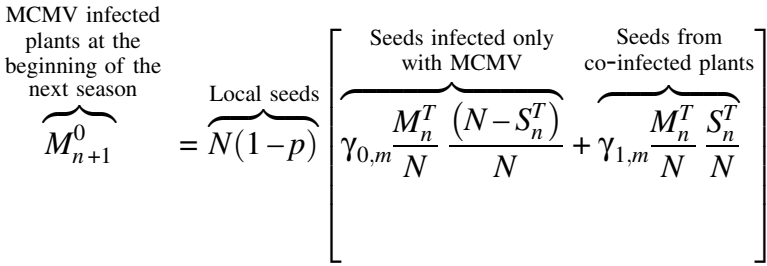

$$
\begin{aligned}
& \underbrace{Z_{m, n+1}^{0}}_{\begin{array}{c}
\text { Primary } \\
\text { inoculum }
\end{array}}=\underbrace{\zeta_{m} M_{n}^{T}}_{\begin{array}{c}
\text { Infected } \\
\text { plants }
\end{array}}
\end{aligned}
$$

Vertical transmission occurs from a proportion $\gamma_{0, m}$ of singly infected plants and a proportion $\gamma_{1, m}$ of coinfected plants. If $\gamma_{0, m} \neq$ $\gamma_{1, m}$, then the dynamics of SCMV and MCMV are coupled over seasons. We assume that maize is always planted during the long rains. However, maize may or may not be planted during the short rains, depending on whether or not the farmer practices crop rotation. We assume that the initial rate of soil transmission depends only on the level of MCMV infection in the previous crop but that soilborne transmission of disease is not possible if crop rotation is practiced; for example:

$$
\zeta_{m}= \begin{cases}\zeta_{0, m} & \text { no crop rotation } \\ 0 & \text { crop rotation }\end{cases}
$$

As before, a similar set of equations but with appropriately subscripted parameters describe the dynamics of SCMV infection between seasons.

Fast/slow timescale argument to simplify the within-season models. For both within-season models, we assume that soil inoculum decays rapidly, such that viral infection from the soil occurs on a relatively fast time scale (Mailleret et al. 2012). This allows us to simplify the mathematical formulation of our model. We show the analysis for the model of MCMV infection-for example, for $M(t)$ and $Z_{m}(t)$ in equation 5 -noting that a similar analysis applies to $S(t)$ and $Z_{s}(t)$.
We let $\tau=t / s$, where $\tau$ is the time variable for the fast time scale, $t$ is that for the slow time scale, and $s$ is a conversion factor linking the slow and fast time scales. We introduce new parameters with $\beta_{m}=s B_{m}$ and $\delta_{m}=s \Delta_{m}$. Assuming that all soil transmission occurs just after the time of planting, the other pathways of infection can be ignored in the fast time scale and, therefore, the differential equations reduce to

$$
\begin{aligned}
\frac{d M}{d \tau} & =\beta_{m} Z_{m}(N-M) \\
\frac{d Z_{m}}{d \tau} & =-\delta_{m} Z_{m}
\end{aligned}
$$

We apply the initial conditions at the beginning of the season, $M_{n+1}^{0}$ and $Z_{m, n+1}^{0}$, to solve equation 8 over the fast time scale. A closed-form solution can be obtained because-after solving for $Z_{m}$-the first part of equation 8 reduces to a monomolecular model with an exponentially decaying rate parameter (Madden et al. 2007). The steady-state solution for the fast time scale (as $\tau \rightarrow \infty)$ is

$$
\bar{M}=N\left(1-\left(1-\frac{M_{n+1}^{0}}{N}\right) \mathrm{e}^{-\frac{\beta_{m} Z_{m, n+1}^{0}}{\delta_{m}}}\right), \bar{Z}_{m}=0
$$

in which $M_{n+1}^{0}$ and $Z_{m, n+1}^{0}$ depend on $M_{n}^{T}$ and $S_{n}^{T}$ (see equation 6). Implicit in this argument is that there is no possibility of carryover of soil inoculum between successive growing seasons unless the soil reservoir is replenished by new MCMV infection.

The expressions in equation 9 are then used as initial conditions, $M(0)=\bar{M}$ and $Z_{m}(0)=\bar{Z}_{m}(=0)$, for the slow time scale equations on the interval $[0, T]$ :

$$
\begin{aligned}
& \frac{d M}{d t}=\left(\alpha_{m} M+\varepsilon_{m}\right)(N-M) \\
& \frac{d Z_{m}}{d t}=0
\end{aligned}
$$

This yields a solution at the end of the season, $M(T)$ and $Z_{m}(T)$, for the MCMV-infected plant density and level of soil infestation at the end of season $n+1, Z_{m}(T)=Z_{m, n+1}^{T}=0$ and $M(T)=M_{n+1}^{T}$, with

$$
M_{n+1}^{T}=\frac{N \mathrm{e}^{\left(\alpha_{m} N+\varepsilon_{m}\right) T}\left(\alpha_{m} \bar{M}+\varepsilon_{m}\right)-\varepsilon_{m}(N-\bar{M})}{\mathrm{e}^{\left(\alpha_{m} N+\varepsilon_{m}\right) T}\left(\alpha_{m} \bar{M}+\varepsilon_{m}\right)+\alpha_{m}(N-\bar{M})}:=f_{m}\left(M_{n}^{T}, S_{n}^{T}\right)
$$

The form of the function $f_{m}$ is complicated to write down but can be inferred by combining equations 6,7 , and 9 . Doing this specifies

TABLE 4. Summary of all state variables used in developing the full model

\begin{tabular}{ll}
\hline Variable & \multicolumn{1}{c}{ Description $^{\mathrm{a}}$} \\
\hline$t$ & Days since planting within one season \\
$M(t)$ & Density (number of plants per field) of MCMV infected plants at time $t$ \\
$S(t)$ & Density of SCMV infected plants at time $t$ \\
$M_{n}^{0}$ & Density of MCMV infected plants at the start of season $n$ \\
$M_{n}^{T}$ & Density of MCMV infected plants at the end of season $n$ \\
$S_{n}^{0}$ & Density of SCMV infected plants at the start of season $n$ \\
$S_{n}^{T}$ & Density of MCMV infected plants at the end of season $n$ \\
$Z_{\mathrm{m}}(t)$ & Primary soil inoculum for MCMV at time $t$ \\
$Z_{\mathrm{s}}(t)$ & Primary soil inoculum for SCMV at time $t$ \\
$Z_{m, n}^{0}$ & Primary soil inoculum for MCMV at start of season $n$ \\
$Z_{s, n}^{0}$ & Primary soil inoculum for SCMV at start of season $n$ \\
$\bar{M}$ & Level of MCMV infection after initial infection by soilborne inoculum \\
$\bar{S}$ & Level of SCMV infection after initial infection by soilborne inoculum \\
$M_{n+1}^{T}=f_{m}\left(M_{n}^{T}, S_{n}^{T}\right)$ & Mapping of the level of MCMV infection from the end of one growing season to the end of the next growing season \\
$S_{n+1}^{T}=f_{s}\left(M_{n}^{T}, S_{n}^{T}\right)$ & Mapping of the level of SCMV infection from the end of one growing season to the end of the next growing season \\
\hline
\end{tabular}

${ }^{a}$ MCMV = Maize chlorotic mottle virus and SCMV = Sugarcane mosaic virus. 
a discrete-time model linking the density of MCMV-infected plants at the end of one season to the densities of SCMV and MCMV infection at the end of the previous season. A similar set of equations define the dynamics of SCMV infection:

$$
S_{n+1}^{T}=\frac{N \mathrm{e}^{\left(\alpha_{s} N+\varepsilon_{s}\right) T}\left(\alpha_{s} \bar{S}+\varepsilon_{s}\right)-\varepsilon_{s}(N-\bar{S})}{\mathrm{e}^{\left(\alpha_{s} N+\varepsilon_{s}\right) T}\left(\alpha_{s} \bar{S}+\varepsilon_{s}\right)+\alpha_{s}(N-\bar{S})}:=f_{s}\left(M_{n}^{T}, S_{n}^{T}\right)
$$

Because we assume that the within-season spread of each virus is independent of the other, the level of MLN infection can be recovered from the model specified in equations 11 and 12 by simply multiplying the proportions of plants infected by each of the constituent viruses. Therefore, equations 11 and 12 completely specify our final mathematical model of MLN dynamics.

Crop rotation. If crop rotation is not practiced, then maize is grown in both the long-rains and short-rains growing seasons and, thus, two iterations of equations 11 and 12 are required per year. However, if crop rotation is adopted, maize is only grown during the long-rains period and, thus, only a single iteration of equations 11 and 12 is required per year (and where $\zeta_{m}=\zeta_{s}=0$; equation 7).

Basic reproduction numbers. Invasion of $M C M V$ when there is no SCMV. We computed the basic reproduction number $R_{0, m}$ for MCMV in the case in which $\varepsilon_{m}=0$ (i.e., when there is no exogenous infection, because otherwise disease would always invade). There is clearly a disease-free equilibrium with $\hat{M}=0$ and $\hat{S}=0$. The basic reproduction number for MCMV is then computed by differentiating equation 11 with respect to $M_{n}^{T}$ and evaluating at the diseasefree equilibrium, leading to:

$$
\mathscr{R}_{0, m}=(\overbrace{\sigma_{m} N}^{\text {Soil }}+\overbrace{\gamma_{0, m}(1-p)}^{\text {Seed }}) \overbrace{e^{\alpha_{m} N T}}^{\text {Vector }}
$$

in which we have introduced a composite parameter governing soil transmission, $\sigma_{m}=\beta_{m} \zeta_{m} / \delta_{m}$, which depends on crop rotation via the parameter $\zeta_{m}$.

Invasion of SCMV when there is no $M C M V$. If $\varepsilon_{s}=0$, a similar expression can obtained for the basic reproduction number of SCMV in the absence of MCMV, $R_{0, s}$, by differentiating equation 12, leading to:

$$
\mathscr{R}_{0, s}=\left(\sigma_{s} N+\gamma_{0, s}(1-p)\right) e^{\alpha_{s} N T}
$$

Again, a composite parameter controlling soil transmission of SCMV has been defined; in this case, $\sigma_{s}=\beta_{s} \zeta_{s} / \delta_{s}$.

\section{ACKNOWLEDGMENTS}

We thank L. Walker for help preparing Figure 1. This work was conducted as a part of the Multiscale Vectored Plant Viruses Working Group at the National Institute for Mathematical and Biological Synthesis, sponsored by the National Science Foundation (NSF) through NSF Award number DBI-1300426, with additional support from The University of Tennessee, Knoxville. We also thank two anonymous reviewers for their helpful comments. N. J. Cunniffe thanks Girton College for support.

\section{LITERATURE CITED}

Adams, I. P., Harju, V. A., Hodges, T., Hany, U., Skelton, A., Rai, S., Deka, M. K., Smith, J., Rox, A., Uzayisenga, B., Ngaboyisonga, C., Uwumukiza, B., Rutikanga, A., Rutherford, M., Richthis, B., Phiri, N., and Boonham, N. 2014. First report of maize lethal necrosis disease in Rwanda. New Dis. Rep. 29:22. Adams, I. P., Miano, D. W., Kinyua, Z. M., Wangai, A., Kimani, E., Phiri, N., Reeder, R., Harju, V., Glover, R., Hany, U., Souza-Richards, R., Deb Nath, P., Nixon, T. Fox, A., Barnes, A., Smith, J., Skelton, A., Thwaites, R., Munford, R., and Boonham, N. 2013. Use of next-generation sequencing for the identification and characterization of Maize chlorotic mottle virus and Sugarcane mosaic virus causing maize lethal necrosis in Kenya. Plant Pathol. 62:741-749.

Allen, L. J. S. 2007. An Introduction to Mathematical Biology. Pearson Education Inc., Upper Saddle River, NJ.

Bassanezi, R. B., Montesino, L. H., Gimenes-Fernandes, N., Yamamoto, P. T., De Queiroz, L., Gottwald, T. R., Amorim, L., and Bergamin Filho, A. 2013. Efficacy of area-wide inoculum reduction and vector control on temporal progress of huanglongbing in young sweet orange plantings. Plant Dis. 97:789-796.

Bockelman, D. L., Claflin, L. E., and Uyemoto, J. K. 1982. Host range and seed-transmission studies of Maize chlorotic mottle virus in grasses and corn. Plant Dis. 66:216-218.

Bond, W. P., and Pirone, T. P. 1970. Evidence for soil transmission of Sugarcane mosaic virus. Phytopathology 60:437-440.

Buhnerkempe, M. G., Roberts, M. G., Dobson, A. P., Heesterbeek, H., Hudson, P. J., and Lloyd-Smith, J. O. 2015. Eight challenges in modelling disease ecology in multi-host, multi-agent systems. Epidemics 10:26-30.

Cabanas, D., Watanabe, S., Higashi, C. H. V., and Bressan, A. 2013. Dissecting the mode of Maize chlorotic mottle virus transmission (Tombusviridae: Machlomovirus) by Frankliniella williamsi (Thysanoptera: Thripidae). J. Econ. Entomol. 106:16-24.

Cunniffe, N. J., Cobb, R. C., Meentemeyer, R. K., Rizzo, D. M., and Gilligan, C. A. 2016. Modeling when, where, and how to manage a forest epidemic, motivated by sudden oak death in California. Proc. Natl. Acad. Sci. USA 113:5640-5645.

Cunniffe, N. J., and Gilligan, C. A. 2010. Invasion, persistence and control in models of soil-borne plant pathogens: The effect of host demography. J. R. Soc. Interface 7:439-451.

Cunniffe, N. J., and Gilligan, C. A. 2011. A theoretical framework for biological control of soil-borne plant pathogens: Identifying efficient strategies. J. Theor. Biol. 278:32-43.

Cunniffe, N. J., Koskella, B., Metcalf, C. J. E., Parnell, S., Gottwald, T. R., and Gilligan, C. A. 2015a. Thirteen challenges in modelling plant disease. Epidemics 10:6-10.

Cunniffe, N. J., Laranjeira, F. F., Neri, F. M., DeSimone, R. E., and Gilligan, C. A. 2014. Cost-effective control of plant disease when epidemiological knowledge is incomplete: Modelling Bahia bark scaling of citrus. PLOS Comput. Biol. 10:e1003753.

Cunniffe, N. J., Stutt, R. O. J. H., Desimone, R. E., Gottwald, T. R., and Gilligan, C. A. 2015b. Optimising and communicating options for the control of invasive plant disease when there is epidemiological uncertainty. PLOS Comput. Biol. 11:e1004211.

Cunniffe, N. J., Stutt, R. O. J. H., van den Bosch, F., and Gilligan, C. A. 2012. Time-dependent infectivity and flexible latent and infectious periods in compartmental models of plant disease. Phytopathology 102:365-380.

De Groote, H., Oloo, F., Tongruksawattana, S., and Das, B. 2016. Communitysurvey based assessment of the geographic distribution and impact of maize lethal necrosis (MLN) disease in Kenya. Crop Prot. 82:30-35.

Deng, T.-C., Chou, C.-M., Chen, C.-T., Tsai, C.-H., and Lin, F.-C. 2015. First report of Maize chlorotic mottle virus on sweet corn in Taiwan. Phytopathology 105:956-965.

Fargette, D., and Vié, K. 1995. Simulation of the effects of host resistance, reversion, and cutting selection on incidence of African cassava mosaic virus and yield losses in cassava. Phytopathology 85:370-375.

Gitonga, K. 2014. Maize lethal necrosis-The growing challenge in Eastern Africa. Online publication. USDA Foreign Agricultural Service Global Agricultural Information Network (GAIN) report. https://gain.fas.usda.gov/ Recent\%20GAIN\%20Publications/Maize\%20Lethal\%20Necrosis\%20-\%20The $\% 20$ growing\%20challenge\%20in\%20Eastern\%20Africa\%20_Nairobi_Kenya_ 12-10-2014.pdf

Goldberg, K.-B., and Brakke, M. K. 1987. Concentration of Maize chlorotic mottle virus increased in mixed infections with maize dwarf mosaic virus, strain B. Phytopathology 77:162-177.

Gottwald, T. R., and Graham, J. H. 2014. Citrus diseases with global ramifications including citrus canker and huanglongbing. CAB Rev. Perspect. Agric. Vet. Sci. Nutr. Nat. Resour. 9:1-11.

Gowda, M., Das, B., Makumbi, D., Babu, R., Semagn, K., Mahuku, G., Olsen, M. S., Bright, J. M., Beyene, Y., and Prasanna, B. M. 2015. Genome-wide association and genomic prediction of resistance to maize lethal necrosis disease in tropical maize germplasm. Theor. Appl. Genet. 128:1957-1968.

Hamelin, F. M., Allen, L. J. S., Prendeville, H. R., Hajimorad, M. R., and Jeger, M. J. 2016a. The evolution of plant virus transmission pathways. J. Theor. Biol. 396:75-89.

Hamelin, F. M., Bisson, A., Desprez-Loustau, M. L., Fabre, F., and Mailleret, L. 2016b. Temporal niche differentiation of parasites sharing the same plant host: Oak powdery mildew as a case study. Ecosphere 7:e01517.

Hamelin, F. M., Castel, M., Poggi, S., Andrivon, D., and Mailleret, L. 2011. Seasonality and the evolutionary divergence of plant parasites. Ecology 92:2159-2166.

Hassan, M., Sahi, G. M., Wakil, W., and Imanat, Y. 2003. Aphid transmission of Sugarcane mosaic virus (SCMV). Pak. J. Agric. Sci. 40:74-76. 
Hibino, H., Roechan, M., and Sudarisman, S. 1978. Association of two types of virus particles with penyakit habang (tungro disease) of rice in Indonesia. Phytopathology 68:1412-1416.

Holt, J., and Chancellor, T. C. B. 1996. Simulation modelling of the spread of rice tungro virus disease: The potential for management by roguing. J. Appl. Ecol. 33:927-936.

Holt, J., and Chancellor, T. C. B. 1997. A model of plant virus disease epidemics in asynchronously-planted cropping systems. Plant Pathol. 46:490-501.

Hyatt-Twynam, S. R., Parnell, S., Stutt, R. O. J. H., Gottwald, T. R., Gilligan, C. A., and Cunniffe, N. J. 2017. Risk-based management of invading plant disease. New Phytol. 214:1317-1329.

Jardine, D. J. 2017. Factsheets: Corn Lethal Necrosis. Online publication. http:// www.plantpath.k-state.edu/extension/publications/cornlethalnecrosis.pdf

Jeger, M. J., Madden, L. V., and van den Bosch, F. 2009. The effect of transmission route on plant virus epidemic development and disease control. J. Theor. Biol. 258:198-207.

Jensen, S. G. 1985. Laboratory transmission of Maize chlorotic mottle virus by three species of corn rootworms. Plant Dis. 69:864-868.

Jensen, S. G., Wysong, D. S., Ball, E. M., and Higley, P. M. 1991. Seed transmission of maize chlorotic mottle virus. Plant Dis. 75:497-498.

Kang'ethe E. 2011. Situation Analysis: Improving Food Safety in the Maize Value Chain in Kenya. Online publication. College of Agriculture and Veterinary Science, University of Nairobi, Kenya. http://www.fao.org/ fileadmin/user_upload/agns/pdf/WORKING_PAPER_AFLATOXIN_ REPORTDJ10thOctober.pdf

Kirimi, L. 2012. History of Kenyan Maize Production, Marketing and Policies. Tegemeo Institute of Agricultural Policy and Development, Nairobi, Kenya.

Kokkinos, C. D., Clark, C. A., Mcgregor, C. E., and Labonte, D. R. 2006. The effect of sweet potato virus disease and its viral components on gene expression levels in sweetpotato. J. Am. Soc. Hortic. Sci. 131:657-666.

Kusia, E. S., and Villinger, I. P. M. 2015. First report of lethal necrosis disease associated with co-infection of finger millet with Maize chlorotic mottle virus and Sugarcane mosaic virus in Kenya. Plant Dis. 99:899-900.

Li, L., Wang, X., and Zhou, G. 2007. Analyses of maize embryo invasion by Sugarcane mosaic virus. Plant Sci. 172:131-138.

Li, L., Wang, X. F., and Zhou, G. H. 2011. Effects of seed quality on the proportion of seed transmission for Sugarcane mosaic virus in maize. Cereal Res. Commun. 39:257-266.

Louie, R. 1980. Sugarcane mosaic virus in Kenya. Plant Dis. 64:944-947.

Lukanda, M., Owati, A., Ogunsanya, P., Valimunzigha, K., Katsongo, K., Ndemere, H., and Kumar, P. L. 2016. First report of Maize chlorotic mottle virus infecting maize in the Democratic Republic of the Congo. Crop Prot. 82:30-35.

Madden, L. V., Hughes, G., and van den Bosch, F. 2007. The Study of Plant Disease Epidemics. American Phytopathological Society, St. Paul, MN.

Madden, L. V., and van den Bosch, F. 2002. A population-dynamic approach to assess the threat of plant pathogens as biological weapons against annual crops. Bioscience 52:65-74.

Mahuku, G., Lockhart, B. E., Wanjala, B., Jones, M. W., Kimunye, J. N., Stewart, L. R., Cassone, B. J., Sevgan, S., Nyasani, J. O., Kusia, E., Kumar, P. L., Niblett, C. L., Kiggundu, A., Asea, G., Pappu, H. R., Wangai, A., Prasanna, B. M., and Redinbaugh, M. G. 2015. Maize lethal necrosis (MLN), an emerging threat to maize-based food security in sub-Saharan Africa. Phytopathology 105:956-965.

Mailleret, L., Castel, M., Montarry, J., and Hamelin, F. M. 2012. From elaborate to compact seasonal plant epidemic models and back: Is competitive exclusion in the details? Theor. Ecol. 5:311-324.

McQuaid, C. F., Sseruwagi, P., Pariyo, A., and van den Bosch, F. 2016. Cassava brown streak disease and the sustainability of a clean seed system. Plant Pathol. 65:299-309.

Mezzalama, M., Das, B., and Prasanna, B. M. 2015. MLN pathogen diagnosis, MLN-free seed production and safe exchange to non-endemic countries. Online publication. International Maize and Wheat Improvement Center (CIMMYT). http://repository.cimmyt.org/xmlui/bitstream/handle/10883/4284/ 56880.pdf?sequence=3

Milne, A. E., Bell, J. R., Hutchison, W. D., van den Bosch, F., Mitchell, P. D., Crowder, D., Parnell, S., and Whitmore, A. P. 2015. The effect of farmers' decisions on pest control with Bt crops: A billion dollar game of strategy. PLOS Comput. Biol. 11:e1004483.

Morales, K., Zambrano, J. L., and Stewart, L. R. 2014. Co-infection and disease severity of Ohio Maize dwarf mosaic virus and Maize chlorotic dwarf virus strains. Plant Dis. 98:1661-1665.

Moritz, G., Brandt, S., Triapistyn, S., and Subramanian, S. 2013. Identification and information tools for pest thrips in East Africa. Online publication. QAAFI Biological Information Technology, University of Queensland, Australia. http://thripsnet.zoologie.uni-halle.de/key-server-neu/data/03030c05-030b4107-880b-0a0a0702060d/media/Html/index.html

Nault, L. R., Styer, W. E., Coffey, M. E., Gordon, D. T., Negi, L. S., and Niblett, C. L. 1978. Transmission of Maize chlorotic mottle virus by chrysomelid beetles. Phytopathology 68:1071-1074.
Nelson, S., Brewbaker, J., and Hu, J. 2011. Maize chlorotic mottle. Plant Dis. 79:1-6.

Niblett, C. L., and Claflin, L. E. 1978. Corn lethal necrosis-A new virus disease of corn in Kansas. Plant Dis. Rep. 62:15-19.

Phillips, N. J., Uyemoto, J. K., and Wilson, D. L. 1982. Maize chlorotic mottle virus and crop rotation: Effect of sorghum on virus incidence. Plant Dis. 66: 376-379.

Quito-Avila, D. F., Alvarez, R. A., and Mendoza, A. A. 2016. Occurrence of maize lethal necrosis in Ecuador: A disease without boundaries? Eur. J. Plant Pathol. 146:705-710.

Redinbaugh, M. G., and Zambrano, J. L. 2014. Control of virus diseases in maize. Pages 391-429 in: Control of Plant Virus Diseases-SeedPropagated Crops. Advances in Virus Research, Vol. 90. G. Loebenstein and N. Katis, eds. Academic Press, Cambridge, MA.

Reynolds, T. W., Waddington, S. R., Anderson, C. L., Chew, A., True, Z., and Cullen, A. 2015. Environmental impacts and constraints associated with the production of major food crops in Sub-Saharan Africa and South Asia. Food Secur. 7:795-822.

Scheets, K. 1998. Maize chlorotic mottle machlomovirus and Wheat streak mosaic rymovirus concentrations increase in the synergistic disease corn lethal necrosis. Virology 242:28-38.

Seabloom, E. W., Borer, E. T., Gross, K., Kendig, A. E., Lacroix, C., Mitchell, C. E., Mordecai, E. A., and Power, A. G. 2015. The community ecology of pathogens: Coinfection, coexistence and community composition. Ecol. Lett. 18:401-415.

Semagn, K., Beyenea, Y., Babub, R., Nair, S., Gowda, M., Das, B., Tarekegne, A., Mugo, S., Mahuku, G., Worku, M., Warburton, M. L., Olsen, M., and Prasanna, B. M. 2015. Quantitative trait loci mapping and molecular breeding for developing stress resilient maize for sub-Saharan Africa. Crop Sci. 55:1449-1459.

Stewart, L. R., Teplier, R., Todd, J. C., Jones, M. W., Cassone, B. J., Wijeratne, S., Wijeratne, A., and Redinbaugh, M. G. 2014. Viruses in maize and johnsongrass in southern Ohio. Phytopathology 104:1360-1369.

Susi, H., Barrès, B., Vale, P. F., and Laine, A.-L. 2015. Co-infection alters population dynamics of infectious disease. Nat. Commun. 6: Article 5975. doi: $10.1038 /$ ncomms 6975

Thomas-Sharma, S., Abdurahman, A., Ali, S., Andrade-Piedra, J. L., Bao, S., Charkowski, A. O., Crook, D., Kadian, M., Kromann, P., Struik, P. C., Torrance, L., Garrett, K. A., and Forbes, G. A. 2016. Seed degeneration in potato: The need for an integrated seed health strategy to mitigate the problem in developing countries. Plant Pathol. 65:3-16.

Thomas-Sharma, S., Andrade-Piedra, J., Carvajal Yepes, M., Hernandez Nopsa, J. F., Jeger, M. J., Jones, R. A. C., Kromann, P., Legg, J. P., Yuen, J., Forbes, G. A., and Garrett, K. A. 2017. A risk assessment framework for seed degeneration: Informing an integrated seed health strategy for vegetatively propagated crops. Phytopathology 107:1123-1135.

Thompson, R. N., Cobb, R. C., Gilligan, C. A., and Cunniffe, N. J. 2016. Management of invading pathogens should be informed by epidemiology rather than administrative boundaries. Ecol. Modell. 324:28-32.

Tollenaere, C., Susi, H., and Laine, A.-L. 2016. Evolutionary and epidemiological implications of multiple infection in plants. Trends Plant Sci. 21:80-90.

USDA. 2014. Maize Lethal Necrosis-The Growing Challenge in Eastern Africa. Washington, DC.

Uyemoto, J. K. 1983. Biology and control of Maize chlorotic mottle virus. Plant Dis. 67:7-10.

Uyemoto, J. K., Bockelman, D. L., and Claflin, L. E. 1980. Severe outbreak of corn lethal necrosis disease in Kansas. Plant Dis. 64:99-100.

van den Bosch, F., and De Roos, A. M. 1996. The dynamics of infectious diseases in orchards with roguing and replanting as control strategy. J. Math. Biol. 35:129-157.

van den Bosch, F., Jeger, M. J., and Gilligan, C. A. 2007. Disease control and its selection for damaging plant virus strains in vegetatively propagated staple food crops; a theoretical assessment. Proc. R. Soc. Lond. B 274:11-18.

Wangai, A. W., Redinbaugh, M. G., Kinyua, Z. M., Miano, D. W., Leley, P. K., Kasina, M., Mahuku, G., Scheets, K., and Jeffers, D. 2012. First report of Maize chlorotic mottle virus and maize lethal necrosis in Kenya. Plant Dis. 96:1582.

Xia, Z., Zhao, Z., Chen, L., Li, M., Zhou, T., Deng, C., Zhou, Q., and Fan, Z. 2016. Synergistic infection of two viruses MCMV and SCMV increases the accumulations of both MCMV and MCMV-derived siRNAs in maize. Sci. Rep. 6: Article 20520.

Xie, L., Zhang, J., Wang, Q., Meng, C., Hong, J., and Zhou, X. 2011. Characterization of Maize chlorotic mottle virus associated with maize lethal necrosis disease in China. J. Phytopathol. 159:191-193.

Zhang, X.-S., and Holt, J. 2001. Mathematical models of cross protection in the epidemiology of plant-virus diseases. Phytopathology 91:924-934.

Zhang, X.-S., Holt, J., and Colvin, J. 2001. Synergism between plant viruses: A mathematical analysis of the epidemiological implications. Plant Pathol. 50:732-746.

Zhao, M., Ho, H., Wu, Y., He, Y., and Li, M. 2014. Western flower thrips (Frankliniella occidentalis) transmits Maize chlorotic mottle virus. J. Phytopathol. 162:532-536. 